\title{
Arrival Metering Precision Study
}

\author{
Thomas Prevot ${ }^{1}$ \\ NASA Ames Research Center, Moffett Field, CA, 94035
}

Joey Mercer ${ }^{2}$, Jeffrey Homola ${ }^{3}$, Sarah Hunt ${ }^{4}$, Ashley Gomez ${ }^{5}$, Nancy Bienert ${ }^{6}$, Faisal Omar ${ }^{7}$, Joshua Kraut $^{8}$ and
Connie Brasil

This paper describes the background, method and results of the Arrival Metering Precision Study (AMPS) conducted in the Airspace Operations Laboratory at NASA Ames Research Center in May 2014. The simulation study measured delivery accuracy, flight efficiency, controller workload, and acceptability of time-based metering operations to a meter fix at the terminal area boundary for different resolution levels of metering delay times displayed to the air traffic controllers and different levels of airspeed information made available to the Time-Based Flow Management (TBFM) system computing the delay. The results show that the resolution of the delay countdown timer (DCT) on the controllers display has a significant impact on the delivery accuracy at the meter fix. Using the "10 seconds rounded" and "1 minute rounded" DCT resolutions resulted in more accurate delivery than " 1 minute truncated" and were preferred by the controllers. Using the speeds the controllers entered into the fourth line of the data tag to update the delay computation in TBFM in high and low altitude sectors increased air traffic control efficiency and reduced fuel burn for arriving aircraft during time based metering.

$\begin{array}{ll} & \\ \text { ADRS } & =\text { Aeronautical Datalink and Radar Simulator } \\ \text { ATM } & =\text { Air Traffic Management } \\ \text { ATD } & =\text { ATM Technology Demonstration } \\ C M S & =\text { Controller Managed Spacing } \\ D C T & =\text { Delay Countdown Timer } \\ E R A M & =\text { En Route Automation Modernization } \\ \text { ETA } & =\text { Estimated Time of Arrival } \\ \text { FIM } & =\text { Flight Deck-based Interval Management } \\ \text { GIM-S } & =\text { Ground-based Interval Management-Spacing } \\ \text { KtS } & =\text { Knots (nautical miles per hour) }\end{array}$

${ }^{1}$ Research Engineer, Human-Systems Integration Division, NASA ARC Mail Stop 262-4, AIAA Senior Member.

${ }^{2}$ Research Psychologist, Human-Systems Integration Division, NASA ARC Mail Stop 262-4, AIAA Member.

${ }^{3}$ Research Psychologist, Human-Systems Integration Division, NASA ARC Mail Stop 262-4, AIAA Member.

${ }^{4}$ Research Psychologist, Human-Systems Integration Division, NASA ARC Mail Stop 262-4.

${ }^{5}$ Research Psychologist, Human-Systems Integration Division, NASA ARC Mail Stop 262-4.

${ }_{7}^{6}$ Research Associate, Human-Systems Integration Division, NASA ARC Mail Stop 262-4.

${ }^{7}$ Research Associate, Human-Systems Integration Division, NASA ARC Mail Stop 262-4.

${ }^{8}$ Research Psychologist, Human-Systems Integration Division, NASA ARC Mail Stop 262-4, AIAA Member.

${ }^{9}$ Research Associate, Human-Systems Integration Division, NASA ARC Mail Stop 262-4, AIAA Member.

${ }^{10}$ Research Engineer, Aviation Systems Division, NASA ARC Mail Stop 210-8, AIAA Member. 


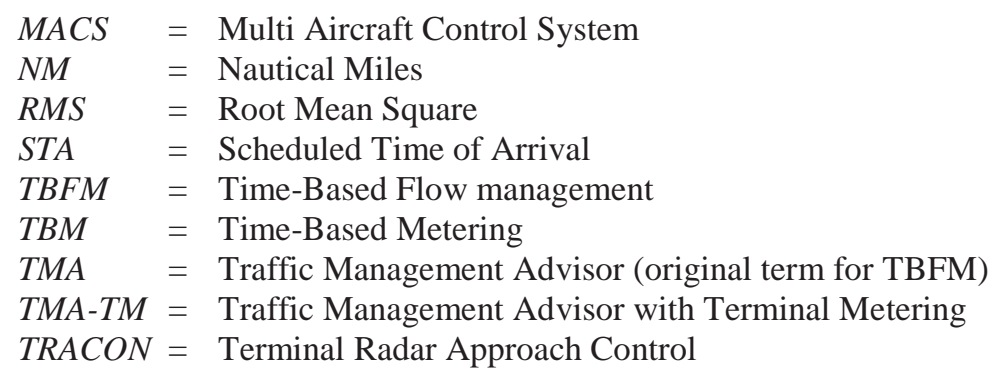

\section{Introduction}

TN May 2014 the Arrival Metering Precision Study (AMPS) was conducted in the Airspace Operations Laboratory 1 at NASA Ames Research Center ${ }^{1}$ to provide supporting data for the introduction of technologies developed under NASA's Air Traffic Management Technology Demonstration 1 (ATD-1). ATD-1 introduces NextGen technologies for the Terminal area, but also requires improved metering precision in the en route arrival airspace. This paper describes purpose, design, method and the results of AMPS. To provide context, we will first briefly introduce ATD-1 and today's en route arrival metering operations.

\section{A. NASA's Air Traffic Management Technology Demonstration-1 (ATD-1)}

ATD-1 integrates NASA technologies for Flight Deck Interval Management (FIM), Controller-Managed Spacing (CMS) tools in the terminal airspace and the Traffic Management Advisor with Terminal Metering (TMATM) to provide fuel-efficient performance-based arrival operations with high throughput ${ }^{2}$ (see Figure 1). TMA-TM creates a de-conflicted efficient schedule for all aircraft at the runway and all merge points. CMS represents a set of controller tools that aid Terminal controllers in issuing primarily speed instructions to meet the schedule. FIM represents an airborne component intended to enable speed management by the flight crew. ATD-1 technologies are currently transitioned from NASA to the FAA. The ground-based technologies, TMA-TM and CMS are expected to build the foundation for Time Based Metering (TBM) in the Terminal area with implementation targeted for the FAA's Time-Based Flow Management (TBFM) work package 3 to be operational between 2017 and $2020^{3}$.

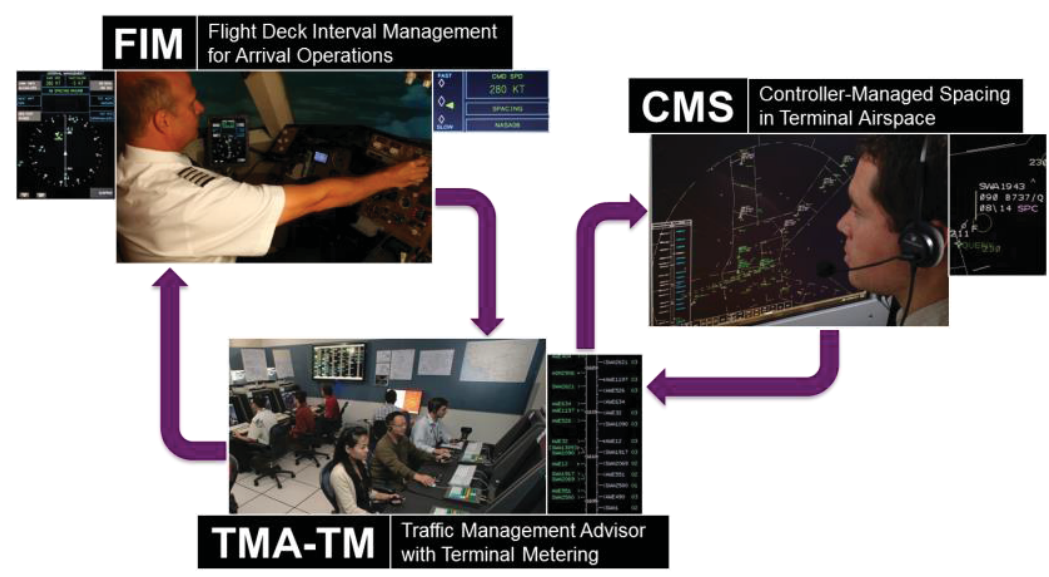

Figure 1: Components of NASA's ATM Technology Demonstration-1 (ATD-1)

\section{B. Time-Based Metering (TBM) in Center and Terminal areas}

The effectiveness of TBM in the terminal environment will be impacted by the accuracy at which aircraft will be delivered from Center controllers working in Air Route Traffic Control Centers (ARTCCs) to terminal controllers operating in Terminal Radar Approach Control (TRACON) facilities. Figure 2 shows a sample current day track plot indicating how aircraft are funneled through an arrival gate, which represents the boundary between the Center and the Terminal airspace. Figure 2 also shows a large amount of vectoring in both, the Center and the Terminal airspace, indicating little

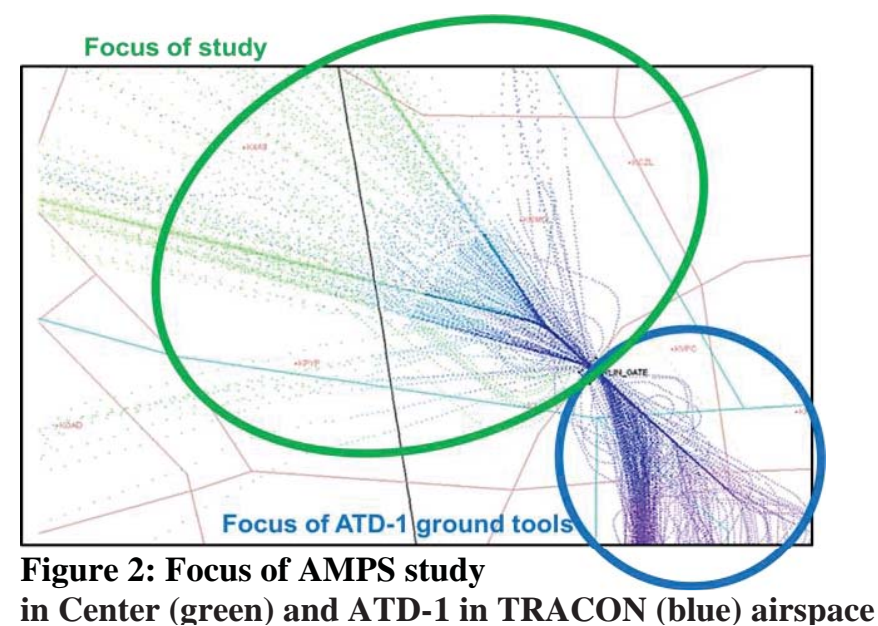


coordination between the two facilities.

Within the ATD-1 and FAA concept of time-based metering Center and Terminal controllers are expected to work together to implement a more efficient arrival plan, generated by the TMA-TM. The TMA-TM will require less delay in the Terminal area than the current day TMA. Center controllers will meter aircraft with increased precision such that Terminal controllers only need to issue a few speed changes. This way aircraft can remain on their routes all the way down to the runway and fly efficient descent profiles with no low altitude vectoring while still meeting their scheduled time of arrival at the runway. In order for this concept to work, Center controllers will need to deliver aircraft with a high time precision to the terminal boundary meter fixes, likely around 30 seconds. However, many Centers today do not conduct time-based metering or are configured to deliver aircraft with only 1 to 2 minutes accuracy. Therefore, it is important to determine whether and how higher delivery accuracy can be achieved with the current or forthcoming TBFM systems for metering in the en route airspace. This question was the subject of the Arrival Metering Precision Study (AMPS) reported in this paper.

\section{Problem: Metering Precision in the Center Airspace}

Arrival metering in the Center airspace is performed using schedules and delay information provided by the enroute components of the TBFM system. When activated this system relays each aircrafts scheduled time of arrival (STA) and current estimated delay value to the air traffic controllers En Route Automation Modernization (ERAM) workstation. The STAs and delays are then presented to the Center controllers in meter lists and as a delay countdown timer (DCT) located near the aircraft target symbol on the radar controller's workstation. The delay can be configured with different resolutions, thus impacting the metering precision. Evaluating the impact of this resolution was the first part of the problem to be addressed in the study and is detailed in the paragraph below.

Secondly, the current day TBFM system uses the current aircraft speed, assigned altitudes and routing information for its underlying trajectory predictions that drive the delay calculation. It has no knowledge of the aircrafts' assigned speed. The new TBFM/ERAM functionality for Ground-based Interval Management - Spacing (GIM-S) will advise speeds to meet times and when accepted use the assigned speeds in its computations, thus improving the trajectory predictions. This functionality was not available and could not be used at the time of the AMPS study. However, AMPS was interested in determining how knowledge of speed intent may impact the metering efficiency and precision. This second part of the problem is described after the delay resolution discussion.

\section{A. Delay Countdown Timer (DCT) resolution}

The first objective of AMPS was to determine the delivery accuracy for different delay resolution values.

As indicated above, the DCTs on the controller's workstation can be configured with different levels of precision. The currently available options are displaying the delay rounded to 10 s of seconds, rounded to the next minute or truncated to minutes. Figure 3 provides an overview of these options as implemented in the AOL's Multi Aircraft Control System (MACS) ${ }^{4}$ research platform which includes a simulation of the ERAM Center controller workstation. Note how different delay values will be reflected by the various DCT resolutions.

Table 1 illustrates the effect of the resolution on how well the actual delay is known. Note that the option of displaying delay to the second is not available in TBFM today.

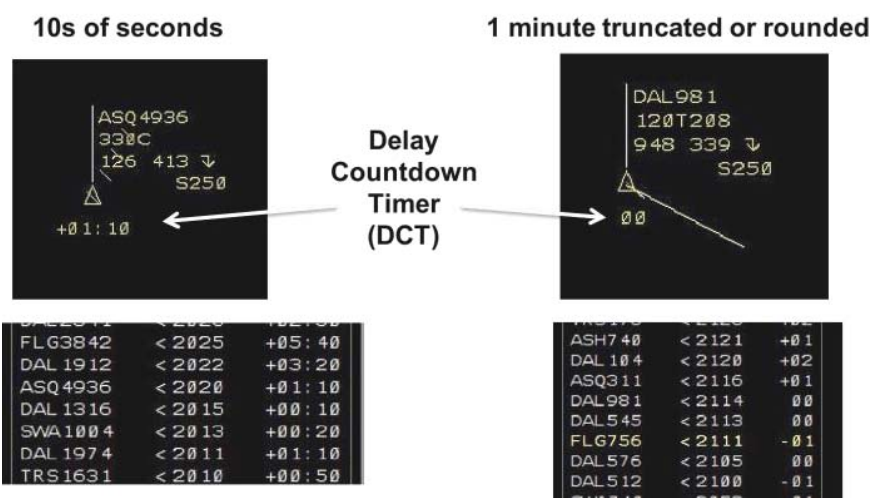

Figure 1: Meter List and Delay Countdown timer (MACS research emulation of Center Controller display)

Table 1: Delay value and DCT for different resolutions

\begin{tabular}{|l|c|c|}
\hline Resolution & Displayed as & Range \\
\hline To the Second (not available) & $00: 46$ & $0: 46$ \\
\hline 10 seconds rounded & $00: 50$ & $00: 45-00: 54$ \\
\hline 1 minute rounded & 01 & $00: 30-01: 29$ \\
\hline 1 minute truncated & 00 & $-00: 59-00: 59$ \\
\hline
\end{tabular}


Table 1 illustrates that for an actual delay of 46 seconds, the "10 seconds rounded" resolution will tell the controller that s/he has to absorb between 45 and 54 seconds to meet the metering time. In the " 1 minute rounded" configuration the controller has to absorb between 00:30 and 1:29 minutes to meet the time precisely, but s/he also knows that if the indication is " 00 ", the aircraft's ETA is within 30 seconds of its STA. Lastly, in the "1 minute truncated" configuration, the controller has no further action to take to meet the time, since his or her indication shows the aircraft to arrive on time. Therefore, if the requirement for Terminal metering were to deliver aircraft to the Terminal boundary within 30 seconds of their STA, a "1 minute truncated" configuration would not allow a controller to reliably achieve this precision. By many estimates about $50 \%$ of the time-based metering operations in the US today are conducted using the "1 minute truncated" configuration.

\section{B. Speed Usage by the TBFM Automation}

The second objective of AMPS was to determine the impact of using (the controller entered 4th line) speed intent in TBFM calculations.

The second issue that was considered to have a potential impact on arrival metering operations in the Center airspace was whether or not the TBFM automation used the controller-entered speeds for its predictions. In the currently fielded system, TBFM estimates the aircrafts indicated air speed based on its tracked ground speed and the wind forecast in that area. This information and nominally adapted descent speeds is then used for the TBFM speed predictions through the Center arrival airspace. As a consequence, any speed changes that the controllers instruct the flight crews to do will only be reflected over time in the delay values shown in the DCT. Therefore controllers have to keep monitoring the DCTs and issue additional instructions if the assigned speed does not have the desired impact. Prior research ${ }^{5,6}$ has indicated that not supplying this speed intent to the TBFM automation can be a major contributor to controller workload and inefficiencies as multiple instructions may be needed to absorb the required delay. Therefore, it was postulated that supplying the speed intent might have a positive impact on efficiency and controller workload. As stated before, GIM-S functionality was not available for the study, so it was decided to supply the speed intent to TBFM using a simple method that was used successfully in prior simulations: Use the speed the controller enters in the fourth line, interpret it as either Cruise speed, Cruise and Descent speed or Descent speed only (based on altitude and distance to meter fix) and send the cruise/descend speed to TBFM. Figure 4 illustrates the effect of this method during metering operations: The example aircraft DAL671 initially required 2:00 minutes delay for a Cruise

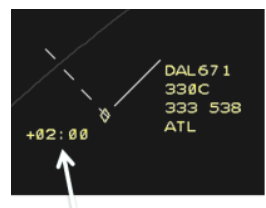

Delay Countdown Timer (DCT) $+02: 00$ at Mach $.77 / 280$ kts $+00: 50$ at $250 \mathrm{kts}$
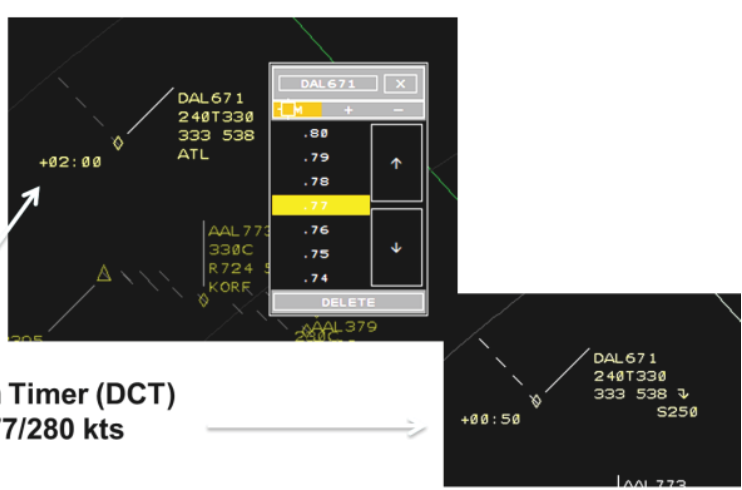

Figure 2: Controller assigned speed updates DCT

Mach of .77 and a descent speed of 280 kts. The controller opens the speed menu, switches it from M to KTS and assigns a speed of $250 \mathrm{kts}$ calibrated air speed (CAS). Given the current aircraft state close to the Top of Descent, this speed is interpreted as cruise and descent speed and sent to TBFM. TBFM recalculates the trajectory using the new speed values and estimates the required delay at $250 \mathrm{kts}$ (CAS) to be 0:50 seconds. This new delay is indicated in the DCT after a few seconds and allows the controller to plan for additional actions if more precision is required. This method does not require any new or additional actions by the controller and basically only provides rapid feedback on his or her actions. It also requires little extra training.

\section{Approach}

The approach to investigating the metering accuracy was to simulate Center arrival metering operations with controllers in the loop interacting with TBFM automation and then vary the two primary parameters of interest: DCT resolution and supplying/not supplying speed intent to TBFM. The operations were intended to mimic the relevant subset of an environment as expected with TMA-TM in place. TMA-TM coordinates all arrivals in generating the schedule for the runways and meter fixes, resulting in even flows to the runways and coordinated, but

4

American Institute of Aeronautics and Astronautics 
uneven flows over each meter fix. In order to simulate this environment over just one corner post the meter fix acceptance rate over that corner post was restricted.

An important factor to consider in configuring TBFM was the delay magnitude. If there was no delay to be absorbed, controllers could simply let the aircraft fly their original profile to have them arrive on time. Small amounts of delay ( $<2$ minutes) can often be absorbed with speed changes, while larger amounts require heading vectors and taking aircraft off route. As a consequence, and supported by previous research ${ }^{6}$, the delay magnitude is a main contributor to task complexity in arrival metering and needs to be considered. Therefore the simulated arrival problems had to mimic the typical delay distribution experienced in metering conditions. This could be achieved by using scenarios and meter fix acceptance rates that resulted in 0 to 6 minutes of delay.

In order to save preparation time and cost AMPS partially re-used traffic scenarios and airspace in Atlanta Center (ZTL) from an earlier study. The Rocket High and Dalas Low sectors depicted in Figure 5 (left) feed traffic over the northwest corner post along the RPTOR 3 arrival (Figure 5, right) into Hartsfield-Jackson Atlanta International Airport (ATL). The airspace could be treated as generic arrival airspace to determine the metering accuracy. The study was not intended to look at specific problems within the Atlanta area.
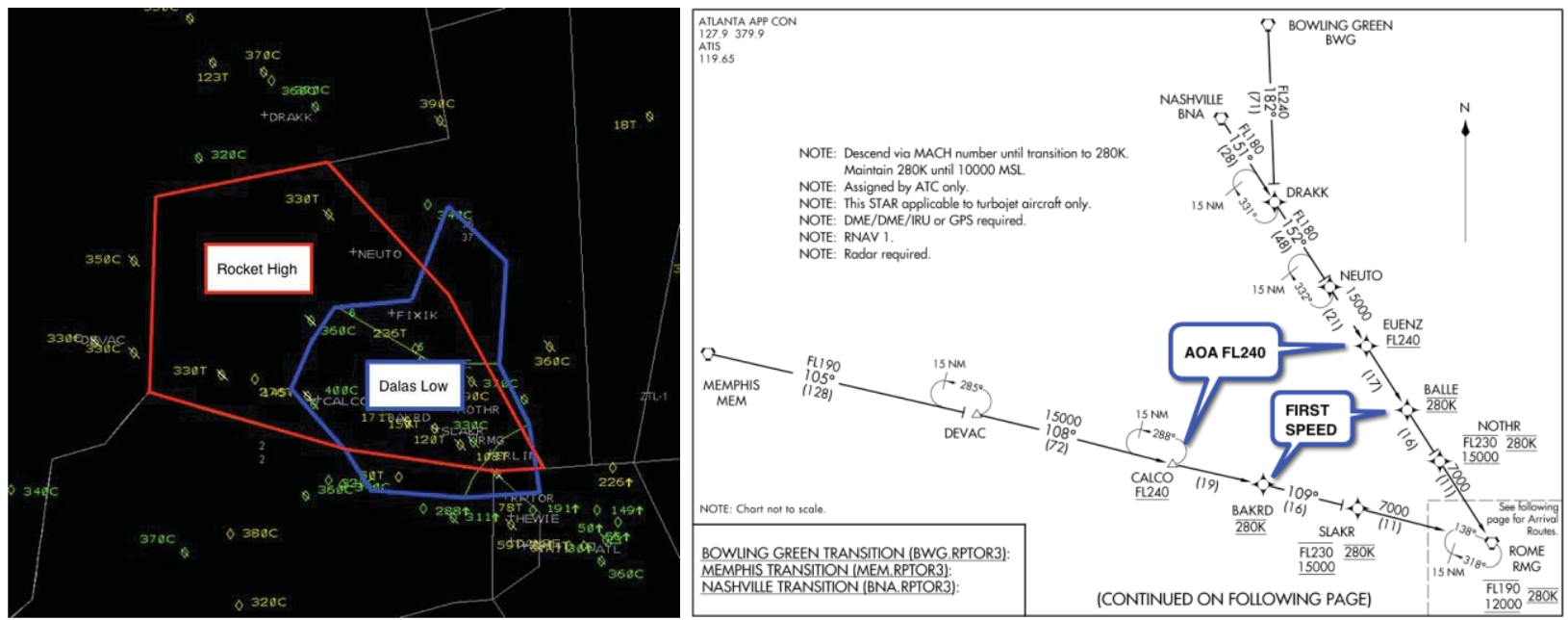

Figure 3: AMPS test environment: Rocket High and Dalas Low test sectors and RPTOR 3 arrival procedure

\section{Method}

The AMPS human-in-the-loop simulation was conducted during one week in spring 2014 in the Airspace Operations Laboratory at NASA Ames Research Center. One day of training was followed by four days of data collection. Experiment design, apparatus, participants and metrics are discussed below.

\section{A. Experiment Design}

AMPS was designed as a 3x2 experiment with three DCT resolution conditions varied over two speed intent conditions. These were varied between runs. In order to balance the desire for randomizing conditions with reducing training difficulty and training effects it was decided to run the conditions in blocks. Each block exercised all three DCT resolution conditions at a single speed intent condition. Delay magnitude was varied within each run. Figure 6 illustrates the general experiment design. Each of the 6 conditions was run 3 times, resulting in 18 runs of 50 minutes. The run schedule is attached in Appendix A. In order to increase experimental power

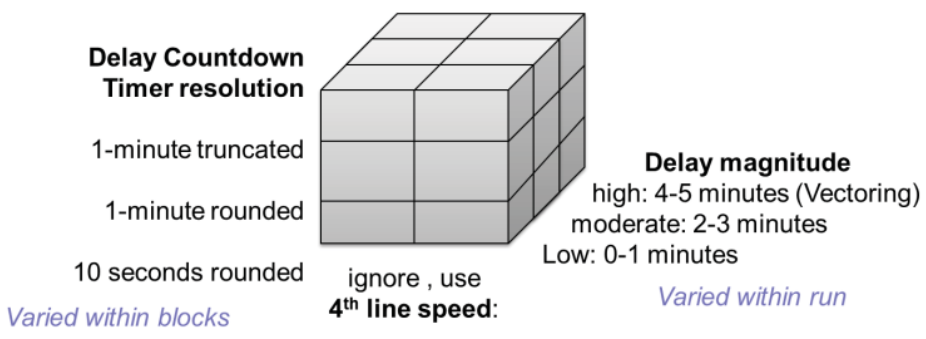
without increasing training and data collection time two controller teams were run in two separate worlds in parallel. This resulted in 6 data runs for each condition, totaling 36 data runs. 


\section{B. Laboratory}

The study was conducted in the areas marked in green and yellow in Figure 7, which depicts the Airspace Operations Laboratory at NASA Ames Research Center. Rooms H208 and H200 were configured as controller rooms for the parallel worlds. The multi aircraft simulation pilots were situated in the H211 area and four airline pilots operated four additional desktop flight simulators in the 280 area.
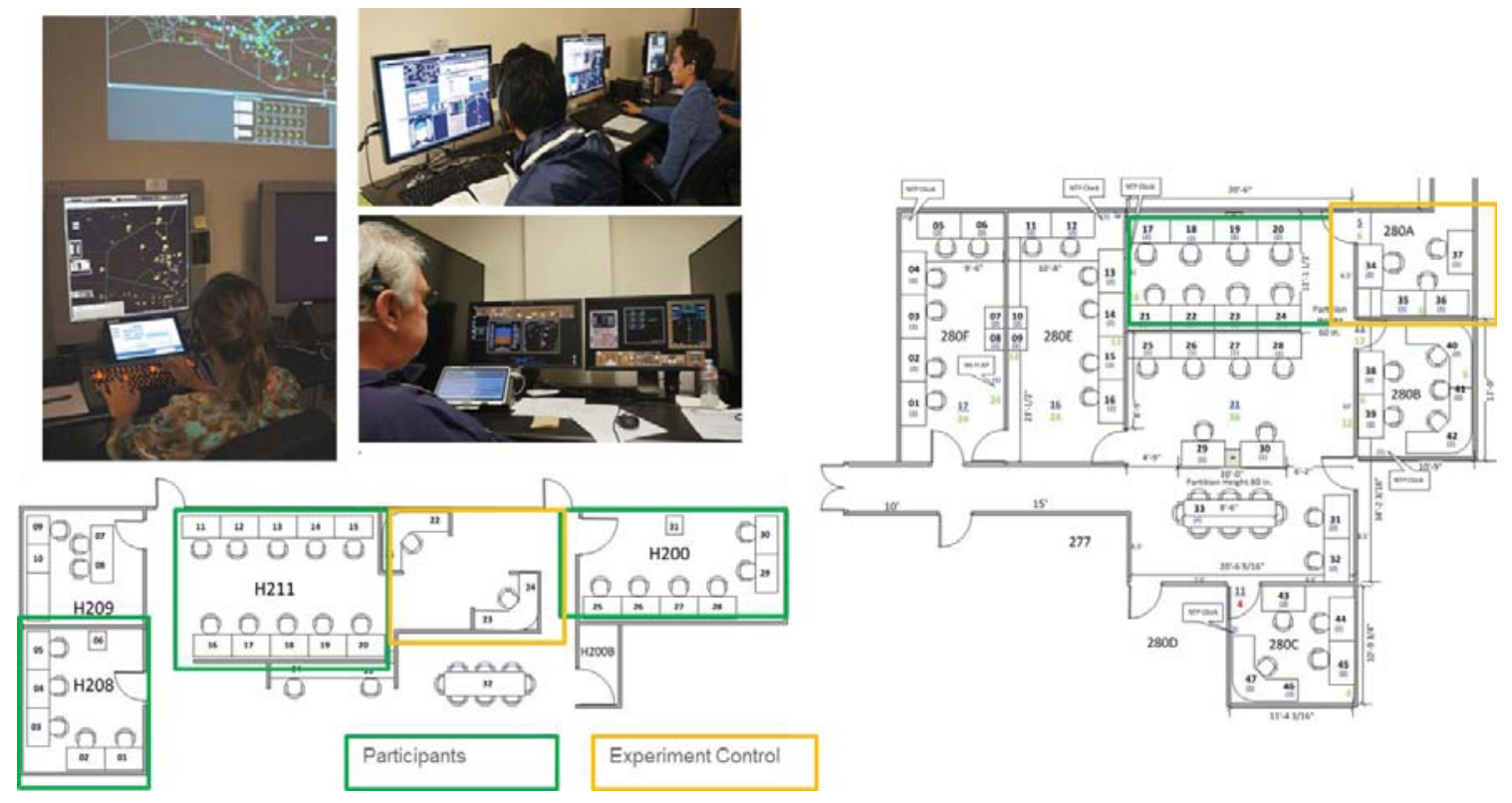

Figure 5: Airspace Operations Laboratory layout and lab scenes

\section{Technologies}

The simulation used the following technologies:

The Multi Aircraft Control System (MACS) ${ }^{4}$ and its simulation hub, the Aeronautical Data Link and Radar Simulator (ADRS), were used as the primary simulation system. This simulation environment was developed in the AOL and represents a comprehensive air traffic research platform with advanced capabilities for scenario and target generation, large scale flight deck simulation, and controller workstations emulating Center, TRACON and Oceanic systems. For this simulation the MACS ERAM Center controller stations were used. Figure 8 shows a snapshot of the Rocket High MACS ERAM display. Arrival aircraft transit the sector from North West to South East. Departures and Overflights transit the sector in various directions.

Four Aircraft Simulation for Traffic Operations Research (ASTOR) ${ }^{7}$ flight deck stations, developed at NASA Langley, were flown by airline pilots to increase procedure and phraseology realism and provide additional data points.

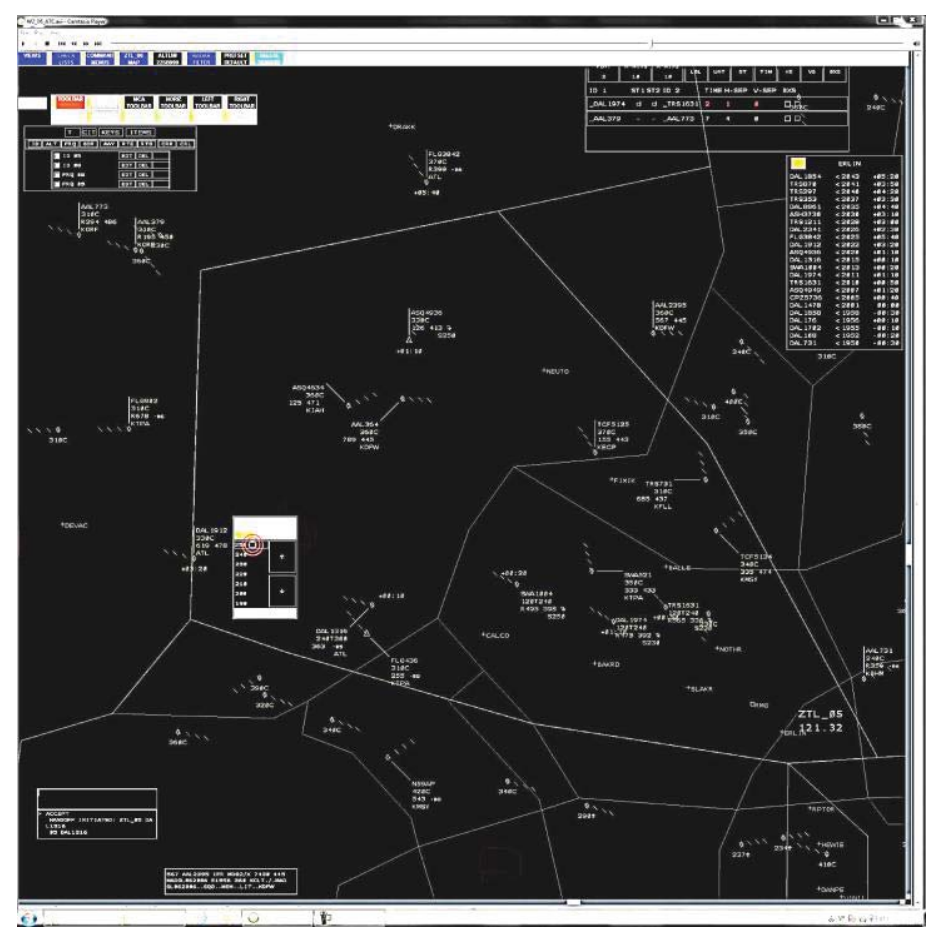

Figure 6: MACS-ERAM display - Rocket High sector

6

American Institute of Aeronautics and Astronautics 
The ATD-1 Research Traffic Management Advisor (RTMA) as of April 2014 was used as TBFM automation. This version was based on RTMA version 3.12. It included all Terminal Metering software, but this was turned off and the standard Atlanta (ZTL) adaption was used. However, the following modifications that NASA had made were used, which were not part of the fielded version at the time:

- The TBFM system used a modified cruise/descent Speed logic that prevented DCT jumps in response to altitude assignments.

- All aircraft default descent speeds were set to 280 knots.

- The TBFM system allowed for processing of cruise/descent speeds from the controller stations for the speed intent conditions.

The TBFM system was operated exclusively by experimenters at the beginning of each run to create the desired delay distribution and to make sure both worlds had very similar schedules. As mentioned earlier the delay distribution was achieved by restricting the arrival rate at the North West gate to 26 - 29 aircraft per hour. This reflected a schedule created for Terminal Metering and resulted in small delays at the beginning of the rush and larger, varying delays later. A typical example timeline is shown in Figure 9. The STAs for each aircraft at the meter fix ERLIN are shown on the right; ETAs are shown on the left. Delay values are shown next to the STAs. Note the uneven STA distribution indicated by the varying gap sizes between subsequent aircraft. This is expected at the meter fix if aircraft from all corner posts are scheduled along performance based arrival routes with optimal runway utilization. In a situation like this controllers cannot approximate meeting STAs with putting aircraft a respective number of miles in trail apart.

\section{Uncertainties}

A number of uncertainties were simulated to increase the realism for the controllers and make sure the automation systems would not be computing values for an unrealistically perfect environment. These uncertainties were considered achievable for the 2017 -2020 primary target time frame of Terminal Metering.

- Flight technical airspeed errors between target airspeed and actual airspeed of $10 \mathrm{kts}$

- Wind errors between forecast winds in the automation systems and environment winds of $10 \mathrm{kts}$ RMS

- Performance modelling errors between automation system models and actual aircraft performance of 5\% (this means that TBFM's mean error of estimating the top of descent location was $5 \%$ of the descent distance, e.g. $5 \mathrm{NM}$ for a $100 \mathrm{NM}$ descent distance)

All aircraft were assumed ADS-B out equipped. Therefore the position and

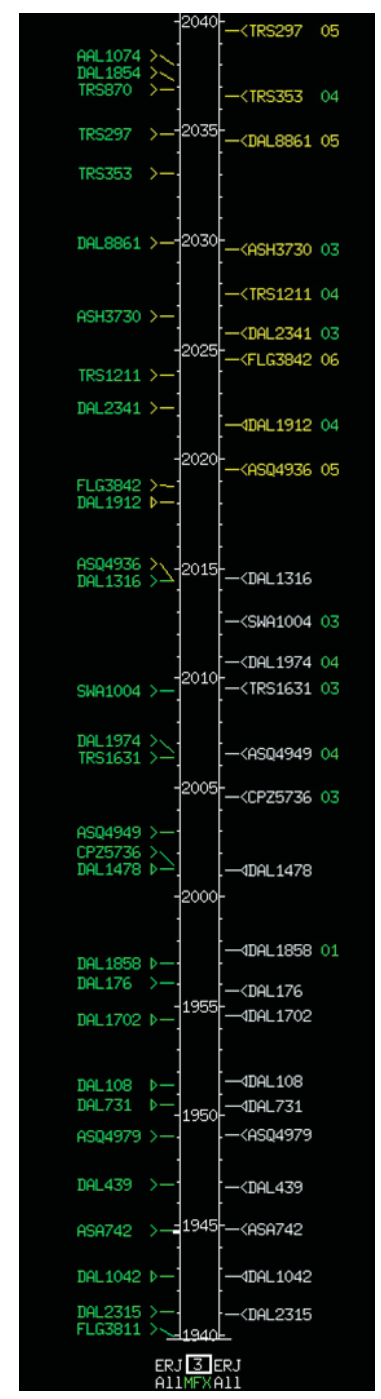

Figure 7 Timeline with typical schedule during AMPS scenario geodetic velocities of all aircraft were known more precisely than in a radar environment.

\section{E. Participants}

The primary participants of the study were four retired air traffic controllers that had retired within less than a year from working the radar controller position. One controller was from Albuquerque Center (ZAB), one from Denver Center (ZDV), and two from Oakland Center (ZOA). All had very limited time-based metering experience and very little prior exposure to the simulation environment. Field observations and discussions with subject matter experts had indicated that many Center controllers in the field may not have much TBM experience or training by the time terminal metering will be introduced. Therefore, it was deemed appropriate to evaluate delivery accuracy with controllers that had little TBM experience and only a very limited amount of TBM training. If the results had indicated infeasibility, a follow-up would have been necessary and additional training requirements had to be concluded. However, as the results show, this was not the case.

Two primary participants worked the test sectors Rocket High and Dalas Low (see Figure 5) in each of the two parallel worlds and did not change their position throughout the study. In addition to the primary participants, four retired controllers worked high altitude and TRACON ghost positions to feed the traffic in and out of the test sectors. Eight general aviation and corporate pilots operated the MACS multi aircraft simulation stations and four airline pilots operated the ASTOR stations. 


\section{F. Operational Procedures}

The following operational procedures were briefed to the controllers: (for reference see Figure 5) The Rocket High controller should absorb as much of the metering delay as possible before handing the aircraft off to the Dalas Low controller. The high altitude controller needed to ensure that the aircraft had been given the RPTOR 3 arrival and the "descend via" clearance. Handoff from high to low needed to occur prior to the waypoints CALCO and EUENZ or the aircraft had to be stopped at flight level 240. The goal of the low altitude controller was to meet the meter time as close to zero as possible prior to handoff to the TRACON. Accounting for the differences in resolution, the low needed as a minimum ensure to achieve $+/-30$ seconds for the tens of seconds DCT resolution and $+/$ - one minute for the minute rounded and minute truncated DCT resolutions.

\section{G. Metrics}

Metrics included objective and subjective measures.

The objective measures included:

- Delivery accuracy

- Flight path efficiency

- Fuel efficiency estimates

- Number of speed assignments

- Number of heading/path assignments

The subjective measures included

- Controller workload

- Controller preference

- Acceptability

All objective measures used data collected by the MACS and TBFM built in data collection systems. The fuel efficiency analysis was done post hoc through an innovative trajectory analysis described in Appendix 2. Most subjective measures were taken in post-run, post-block and post-simulation electronic questionnaires that the controllers completed at their station.

Delivery accuracy and flight path efficiency were analyzed using three arcs around the meter fix ERLIN as shown in Figure 10. These arcs represent approximately the following areas:

The $125 \mathrm{NM}$ arc approximates the area at which the Rocket High altitude controller takes the ownership over the aircraft and starts to control it. At this arc all aircraft STAs were "frozen", which means assigned by TBFM, but no controller had actually tried to absorb the delay. Therefore, data for this arc represent the entry conditions into the test airspace.

The $65 \mathrm{NM}$ arc approximates the area in which control gets transferred from the high altitude controller to the Dalas Low altitude controller. Therefore, it can be used to analyze the effect of the high altitude controller's actions and represents the entry values for the low altitude controller. The $5 \mathrm{NM}$ arc represents the area at which aircraft typically get handed off to the TRACON and the requirements for terminal metering must be met. Measurements at this arc are used as exit values from the test airspace and are therefore the main metrics of interest.

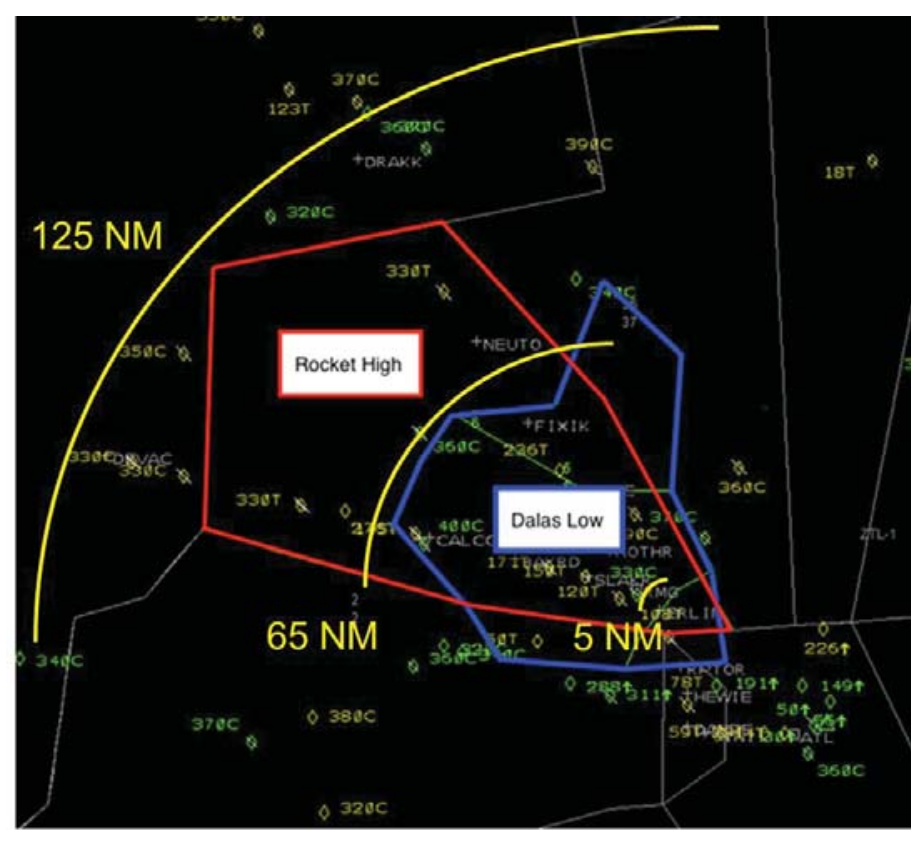

Figure 8: Arcs used for primary metrics 


\section{Results}

This section contains the primary results from the AMPS study in compiled form. In some cases more detailed results are available in the appendix.

\section{A. Delivery accuracy}

Delivery accuracy was measured as delay (STA - ETA) at the three arcs. The delay was calculated by TBFM with an accuracy of tens of seconds. 6 histograms were produced for each arc representing the 6 different conditions. The histograms for all arcs are available in Appendix C or this section. Each histogram represents all arrivals that crossed the respective arc during 3 data collection runs each in the two worlds. The blue bars show the number of aircraft which had a delay value within the respective bin and references the left $\mathrm{Y}$ axis. The red line shows the cumulative percentage of aircraft with delay values up to the respective bin and references the right $Y$ axis.

Figure 11 shows the histogram for the 125 NM arc in the " 1 Minute Rounded/No $4^{\text {th }}$ line" condition to illustrate the entry conditions into the test airspace. This histogram is representative of all $125 \mathrm{NM}$ histograms as aircraft were only minimally controlled outside the test airspace. Figure 11 shows that of the 131 aircraft crossing the $125 \mathrm{NM}$ arc during the 6 data collection runs, $30 \%$ of aircraft entering required less than two minutes delay, meaning speed control should have been sufficient to absorb it. $40 \%$ of arrivals required two to three minutes of delay, meaning moderate control actions to change speed, altitude and/or heading are required. $30 \%$ of aircraft required 4 minutes or more delay, which could only be achieved with substantial heading vectors.

Figure 12 shows the histogram for the same condition at the $65 \mathrm{NM}$ arc. 143 aircraft crossed this arc. These are 12 data points more than at the 125 NM arc, because some arrival aircraft per scenario were initialized between the $125 \mathrm{NM}$ arc and the $65 \mathrm{NM}$ arc, which required no delay. This explains the higher bar at the 0 delay bin. Additionally, when the aircraft were handed off to the low altitude controller the high altitude controller had already eliminated any delays over 3 minutes and generally reduced

\section{Minute Rounded / No 4th Line}

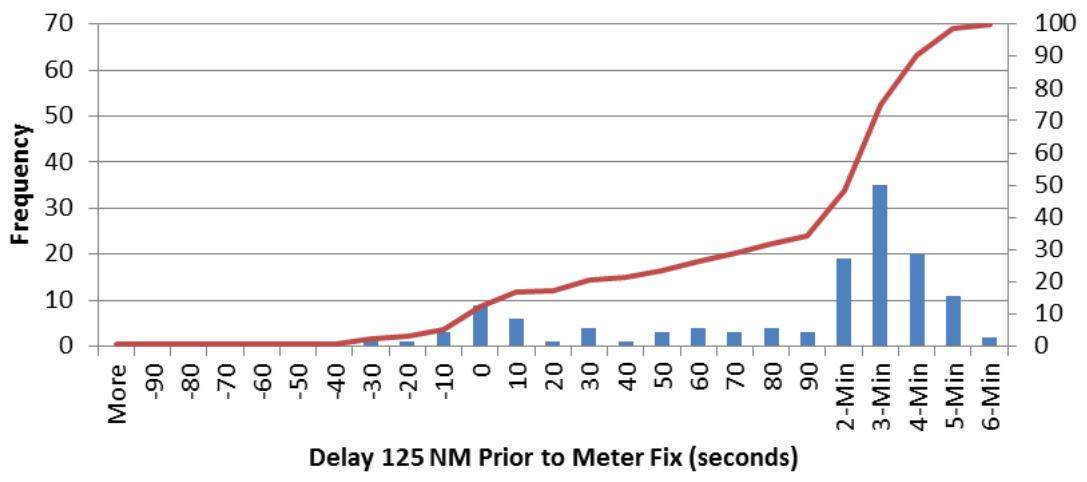

Figure 9: delay at $125 \mathrm{NM}$ arc representing entry conditions into test airspace

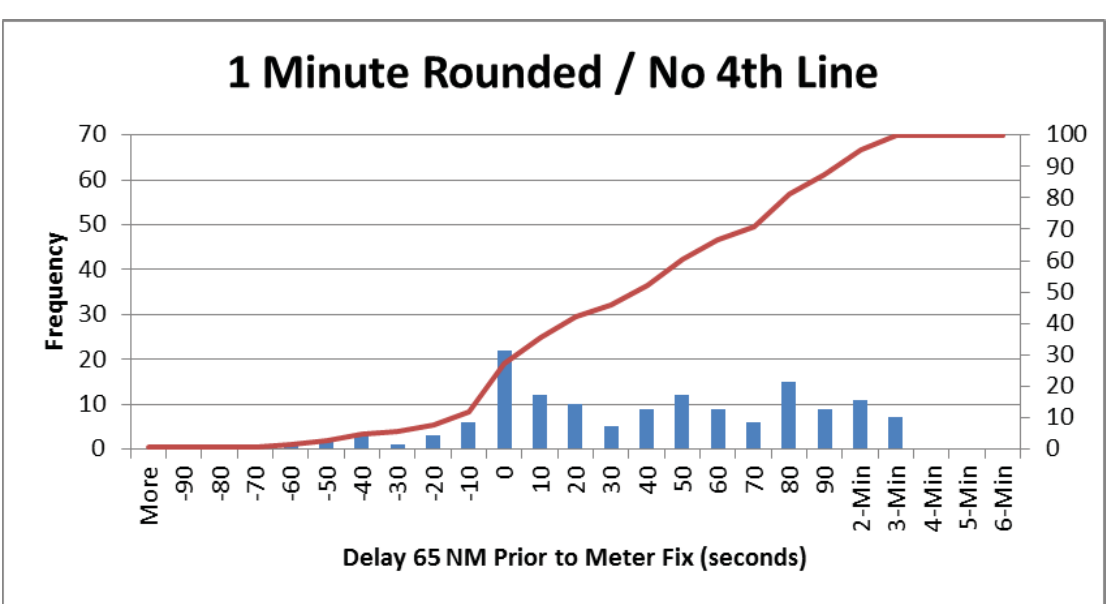

the delays to a manageable value for the low altitude controller.

Figure 13 shows the histograms for all conditions at the $5 \mathrm{NM}$ arc. The left column shows from top to bottom the three DCT conditions combined with the "Yes $4^{\text {th }}$ Line" condition in which controller entered speeds were sent to TBFM to update the DCT within seconds. The right column shows the same DCT conditions for the current day "No $4^{\text {th }}$ Line" condition. The " 1 Minute Rounded / No $4^{\text {th }}$ line" chart reflecting the same condition as Figures 11 and 12 is in the middle right position. Similar histogram sets for the $125 \mathrm{NM}$ arc and the $65 \mathrm{NM}$ arc are available in 
Appendix C. The histograms at the 5 NM arc in Figure 13 are treated as the delivery accuracy to the TRACON and therefore the most important data set for assessing the delivery accuracy that the Center controllers achieved to precondition the aircraft for fine-tuning the speeds within the terminal area TBM.
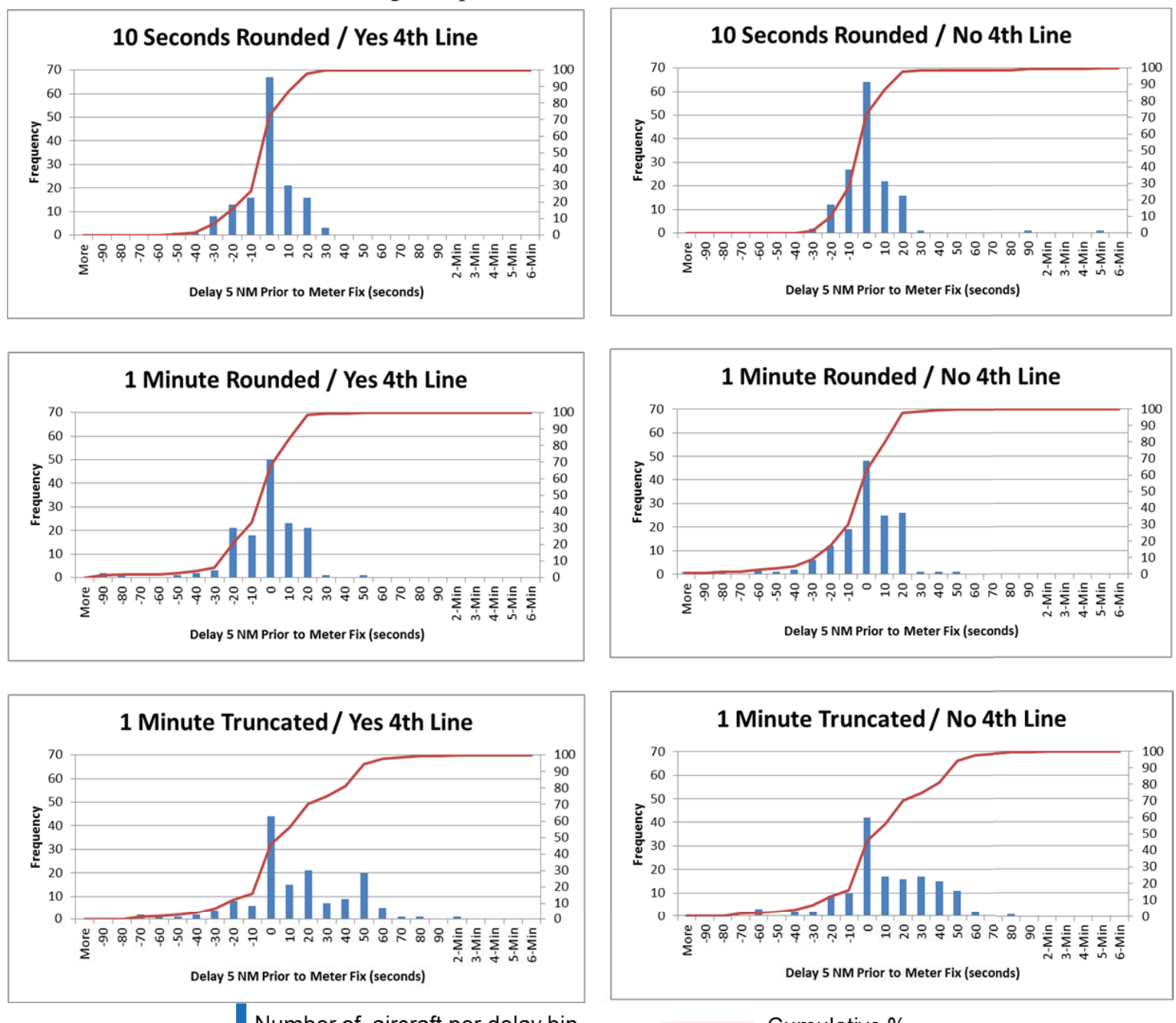

Number of aircraft per delay bin

Figure 11: Histograms for delivery accuracy at the 5 NM arc around the Meter Fix ERLIN

Figure 13 shows overall good delivery accuracy across conditions, indicating that the controllers were able to successfully meter all arrivals. Each histogram represents 146 to 149 aircraft arrivals crossing the 5 NM arc. Note that the peaks at 0 delay also include a number of aircraft that did not require any delay and control instructions. This includes the average 21 aircraft that did not require delay at the $65 \mathrm{NM}$ arc and several more aircraft that were initialized in the low altitude sector at the beginning of the scenario

The results show that there are differences in the metering accuracy between DCT conditions, but no substantial differences for a given DCT resolution in the accuracy between the $4^{\text {th }}$ line conditions. The " 10 seconds rounded" conditions at the top show the highest number of aircraft in the 0 second bin with a narrow normal distribution around it. This represents the highest metering precision. The "1 minute rounded" condition exhibits more clustering because the DCT resolution can only inform controllers whether the aircraft are within 30 seconds of the 0 delay value. 30 seconds or more were indicated as a non-zero number in the DCT. Therefore, aircraft are more evenly distributed within the -20 to +20 bins. (Note that delays are only known with 10s of seconds' accuracy) The biggest difference between conditions can be seen between the " 1 minute truncated" and all other conditions. Since the DCT will only indicate when aircraft are within one minute of the 0 delay value, delays are fairly evenly distributed between -20 and 50 seconds bins. The reasons for having more aircraft arrive early than late are that (a) the version of TBFM used in the study never scheduled an aircraft earlier than its ETA and (b) controllers usually took action 
until the delay value dropped from " 01 " to " 00 ", which was the case as soon as the aircraft had less than 60 seconds of delay to absorb.

To allow a more direct comparison between conditions and an assessment which condition meets certain delivery accuracy, Figure 14 combines the cumulative \% graphs for all conditions into one plot. The "10 seconds rounded" and " 1 minute rounded" conditions produced very similar delivery accuracy. The "1 minute truncated" condition resulted in larger delays at the meter fix. Almost all aircraft were delivered within +/- 60 seconds.

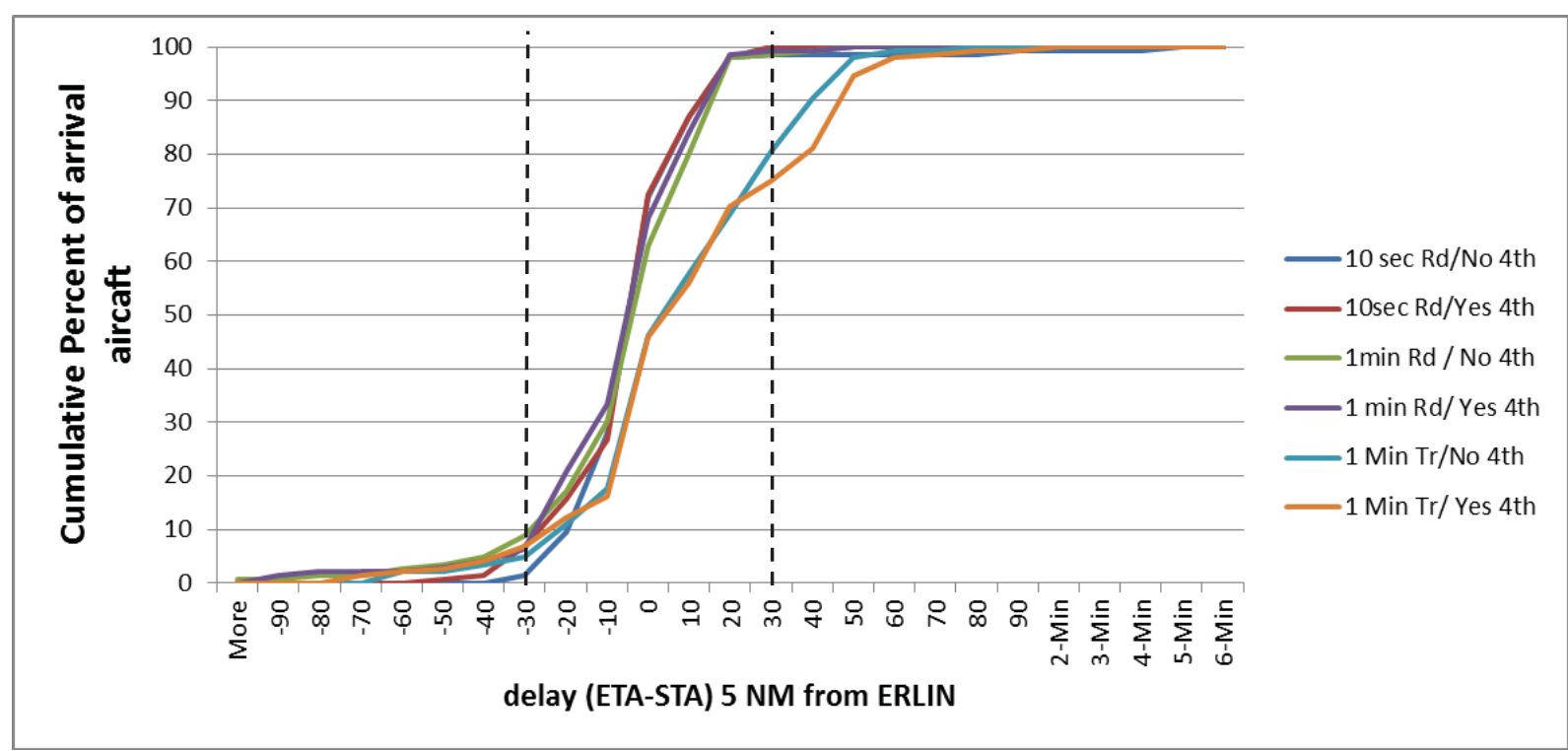

Figure 12: delivery accuracy $5 \mathrm{~nm}$ from meter fix ERLIN across all conditions

The dashed lines in Figure 14 are drawn to indicate which percentage of aircraft achieved a +/- 30 seconds accuracy at the meter fix for a given condition. The results from the study are shown in Table 2.

Table 2: Percent of aircraft arriving within $+/-30$ seconds at the ERLIN meter fix

\begin{tabular}{|c|c|c|c|c|}
\hline Condition & $\begin{array}{l}\text { More than } 30 \\
\text { seconds late }\end{array}$ & Less than 30 seconds early & $\begin{array}{l}\text { Within +/- } 30 \\
\text { seconds }\end{array}$ & By DCT condition \\
\hline 10sec Rd/Yes 4th & $6.8 \%$ & $100.0 \%$ & $93.2 \%$ & \multirow[b]{2}{*}{$95.3 \%$} \\
\hline $10 \mathrm{sec}$ Rd/No 4th & $1.4 \%$ & $98.7 \%$ & $97.3 \%$ & \\
\hline $1 \mathrm{~min} \mathrm{Rd} / \mathrm{Yes} 4 \mathrm{th}$ & $6.2 \%$ & $99.3 \%$ & $93.1 \%$ & \multirow[b]{2}{*}{$91.4 \%$} \\
\hline 1min Rd / No 4th & $8.9 \%$ & $98.6 \%$ & $89.7 \%$ & \\
\hline $1 \mathrm{Min} \mathrm{Tr} /$ Yes 4th & $6.8 \%$ & $75.0 \%$ & $68.2 \%$ & \multirow[b]{2}{*}{71.9 \% } \\
\hline $1 \mathrm{Min}$ Tr/No 4th & $4.8 \%$ & $80.3 \%$ & $75.5 \%$ & \\
\hline
\end{tabular}

As the combined DCT value in the last column of table 2 shows, in this study the controllers delivered $95.3 \%$ aircraft within +/-30 seconds to 5 NM arc from the meter fix ERLIN in the "10 seconds rounded" DCT conditions. In the " 1 minute rounded" conditions they delivered $91.4 \%$ within $+/-30$ seconds to the same arc and the " 1 minute truncated" conditions resulted in $71.9 \%$ of aircraft within $+/-30$ seconds at the $5 \mathrm{NM}$ arc. 
The $4^{\text {th }}$ line condition had little and inconsistent impact on the delivery accuracy at the meter fix. It had however an impact on the delivery accuracy from the high altitude to the low altitude controller. Figure 15 illustrates this effect. It shows the percentage of aircraft within +/-30 seconds at the three different arcs starting at the $125 \mathrm{NM}$ arc at the bottom.. In all "Yes $4^{\text {th }}$ line" conditions more aircraft are within +/-30

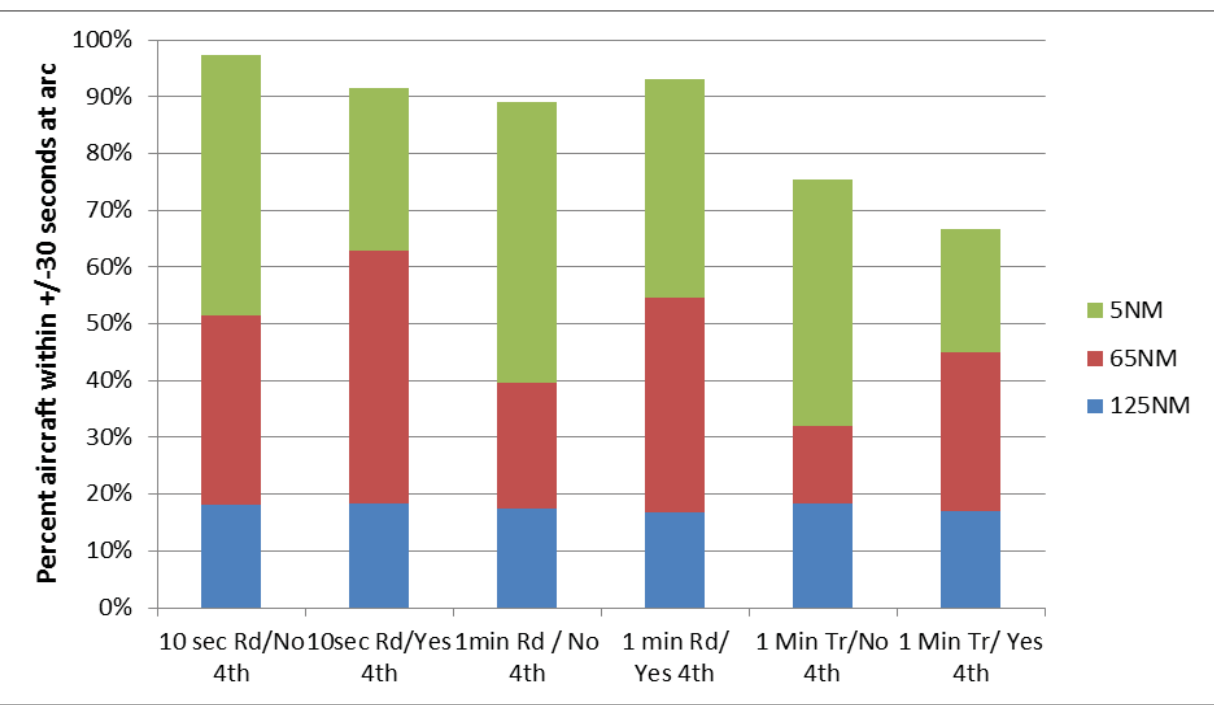

Figure 13: percent aircraft within $+/-30$ seconds at the 3 arcs

seconds at the $65 \mathrm{NM}$ arc than their corresponding "No $4^{\text {th }}$ line" condition. This indicates that the high altitude controllers were more effective absorbing the delay earlier when they could immediately see the impact of their speed assignment on the DCT.

In the next section we will discuss how this more effective delay management with the $4^{\text {th }}$ line speed translated into increased efficiency.

\section{B. Path Efficiency}

An analysis of the path efficiency for the six conditions was conducted using only those aircraft that transitioned all three arcs. These were between 94 and 97 arrivals per condition with a total $\mathrm{n}$ of 576 arrivals. Path efficiency was measured as extra track NM between the different arcs. Extra track NM is the difference between the actual NM flown between the arcs and the direct distance $(=60 \mathrm{NM})$ between the arcs. Figure 16 illustrates the result. Overall the "10 seconds rounded" condition without $4^{\text {th }}$ line input to TBFM resulted in the highest amount of extra track NM during the $120 \mathrm{NM}$ section from the $125 \mathrm{NM}$ arc to the $5 \mathrm{NM}$ arc. As discussed before, this condition resulted in the best precision but added more than 10 NM flight distance. The "1 minute rounded/ No $4^{\text {th }}$ line" condition used only slightly fewer extra track NM. The "1-minute truncated" conditions added fewer extra NM, but did not result in a very accurate flow. This general trade-off between precision and efficiency was mostly compensated for in the "Yes $4^{\text {th }}$ line" conditions, which reduced the extra track NM for the more precise conditions (10s, 1 minute rounded) by $30 \%$ and resulted in only slightly less efficient flight paths than the most efficient, but least accurate condition ("1 minute truncated, Yes $4^{\text {th }}$ line")

Flight path length is only an indication of efficiency used as a stand in, because the simulation

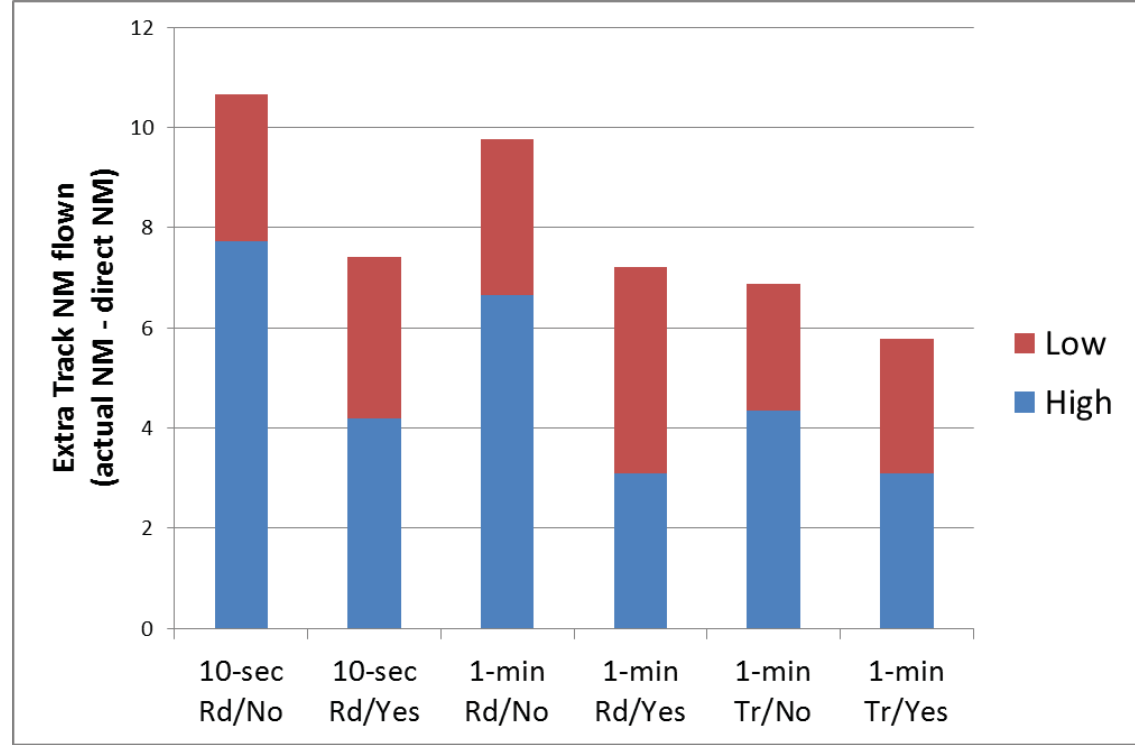

Figure 14: Extra track miles flown between the arcs (High $=125 \mathrm{NM}$ arc to $65 \mathrm{NM}$ arc, Low $=65 \mathrm{NM}$ arc to $5 \mathrm{NM}$ arc) 
did not have a reliable fuel model. We were however interested in determining whether the different conditions actually resulted in fuel savings. The next section will discuss this analysis.

\section{Fuel Burn Analysis}

Fuel burn was estimated post hoc by synthesizing trajectories that closely matched the actually flown trajectories and then computing the fuel for the synthesized trajectories. The analysis took advantage of the fuel burn models integrated with the Trajectory Synthesizer (TS) ${ }^{8}$ of the Center TRACON Automation (CTAS) ${ }^{9}$. The method is described in detail in Appendix B.

Fuel burn was calculated for arrival flights using the portion of trajectory between a track point 140 NM from the meter fix ERLIN and another track point $5 \mathrm{nmi}$ from ERLIN. The distance of $140 \mathrm{NM}$ was selected to include the effects of all controller-issued clearances upstream. Only the flights that traversed the full length from the $140 \mathrm{nmi}$ distance to $5 \mathrm{nmi}$ were selected for analysis. A few additional flights were eliminated from the analysis due to data interruption issues. The results contained a total of 444 flights' fuel burn, corresponding to 74 flights for each of the six tool conditions.
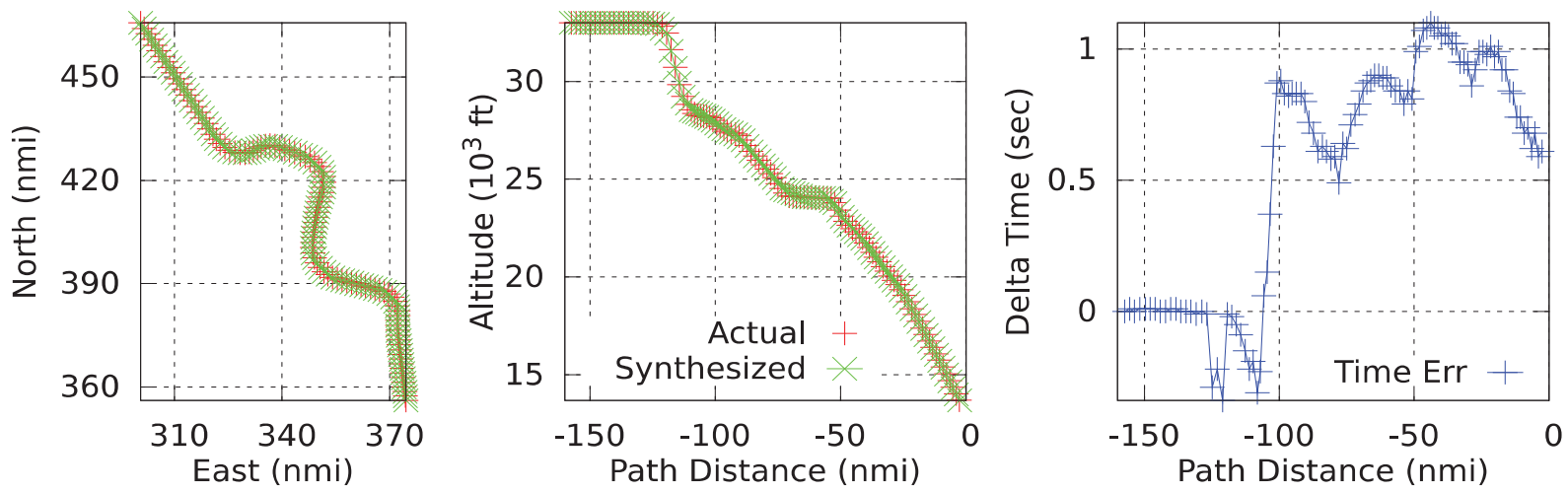

Figure 15: Comparison of synthesized and actual trajectories for a typical flight.

All synthesized trajectories were closely fitted to the actual trajectories. Comparison of the synthesized trajectory to the actual trajectory showed that the maximum cross track error, the maximum altitude error, and the maximum time error were less than $0.3 \mathrm{nmi}, 500 \mathrm{ft}$, and 5 seconds, respectively, for most flights. Only one flight had a maximum cross track error greater than $1 \mathrm{nmi}$, and only one flight (a different one) had a time error greater than 10 seconds.

Figure 17 shows the comparison for a typical flight in terms of their horizontal paths (left plot), altitude profiles (middle), and the time error (right).

Figure 18 shows the breakdown of the total fuel burn by tool conditions. The first observation is that using the $4^{\text {th }}$ line speed reduced the total fuel burn by $5 \%$ to $9 \%$. The second observation is that a finer delay resolution resulted in higher fuel burn. Without the $4^{\text {th }}$ line

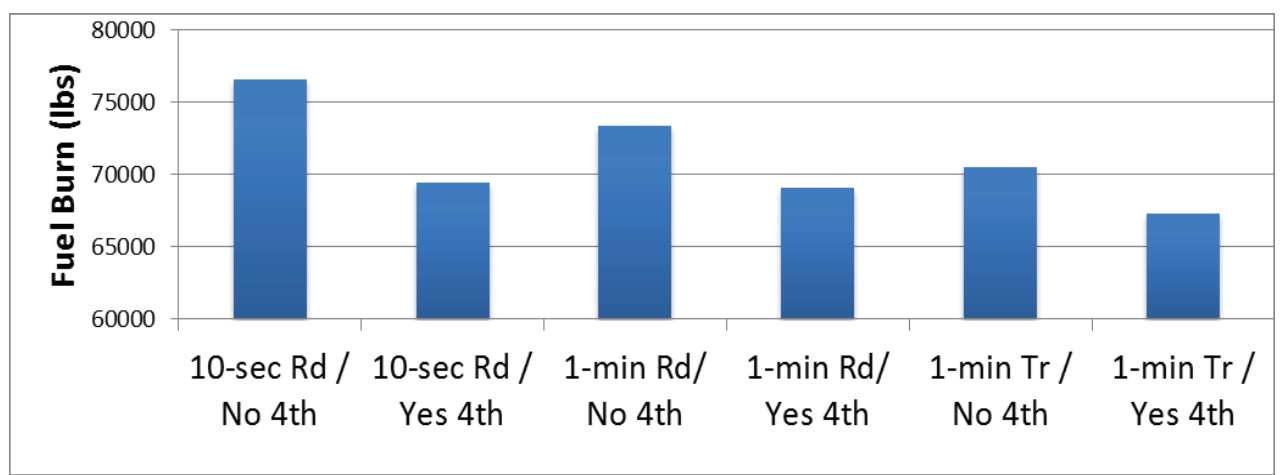

Figure 16: Fuel burn at different tool conditions speed, the "10 seconds rounded" delay resolution resulted in 9\% more fuel burn than the "1 minute truncated" delay resolution. The observations are in accordance with the results of flight path efficiency, indicating a strong correlation between flight path length and fuel burn. 
The question of why using the $4^{\text {th }}$ line speeds in TBFM results in more efficient flight paths with less fuel burn can be answered by analyzing the control instructions.

\section{Air traffic control instructions}

In order to examine the differences in instructions issued to the aircraft the controller's data entries were analyzed for all runs and all conditions. The general patterns align with the patterns observed for the accuracy and the path efficiency analysis. Figures 19 and 20 show the speed and heading/route instructions issued for each of the conditions.

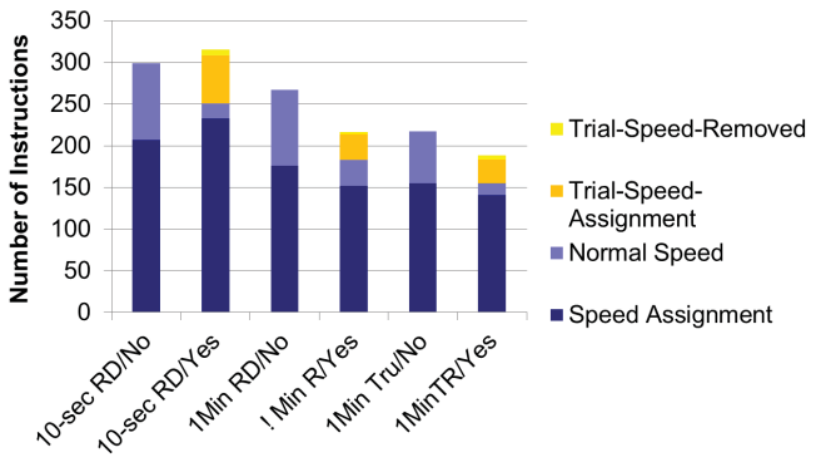

Figure 19: Speed instructions entered by controllers

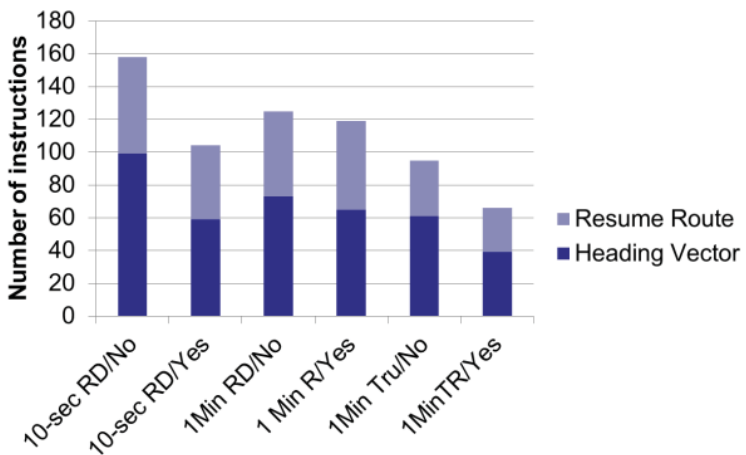

Figure 20: Heading/route instructions

Figure 19 shows the number of speed instructions that were issued to the flight crews as well as the number of Trial-Speed Assignments. These trial assignments indicated in orange and yellow colors represent assignments that the controllers put into the $4^{\text {th }}$ line, saw the new delay in the DCT and decided to issue a different instruction, because they did not like the result. They basically used TBFM to trial plan different speed assignments in order to find the most effective one. As a result, the number of issued speed assignment is lower for the "Yes $4^{\text {th }}$ line" conditions than for their respective "No $4{ }^{\text {th }}$ line" conditions. (Note that controllers were instructed that it would be better to input a speed assignment in the Yes $4^{\text {th }}$ line conditions than using normal speed, because an explicit speed assignment would keep the automation up to date better.) In addition to reducing the number of speed instructions the more accurate automation feedback from forwarding the $4^{\text {th }}$ line speeds to TBFM also reduced the number of heading clearances in all DCT conditions.

The overall impact of using the $4^{\text {th }}$ line speeds in TBFM is illustrated in Figure 21. This chart represents all speed and heading/route instructions to the 860 arrival aircraft that the controllers entered into the $4^{\text {th }}$ line of the data tag averaged per arrival aircraft. This provides an indication of the average number of instructions the controllers issued to each aircraft while it transitioned the 120 NM of arrival airspace.

Without using the $4^{\text {th }}$ line speed in TBFM controllers issued an average of 1.93 speed and .84 heading/route instructions. With the fourth line controllers issued 1.45 speed and .71 heading/route instructions. This is an overall reduction of $22 \%$ in instructions controllers issued and flight crews implemented, allowing for fewer interruptions during the descent.

\section{E. Controller Workload}

Controller workload was measured in two ways: in real time using a MACS built-in workload assessment keypad, modelled after the ATWIT methodology ${ }^{10}$ and after

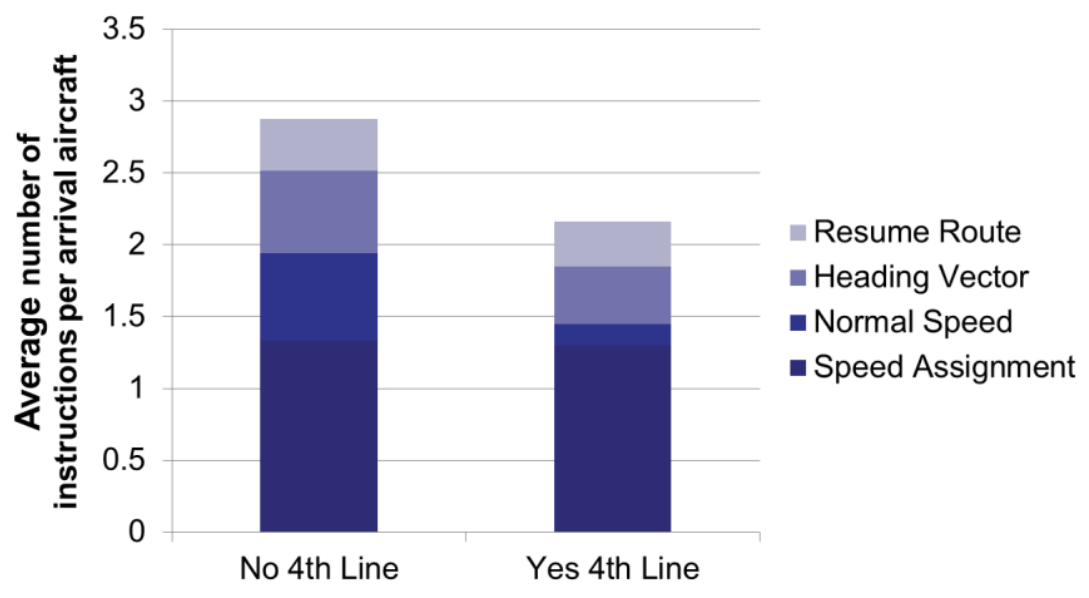

Figure 21: Comparison of control instruction with and without using controller assigned $4^{\text {th }}$ line speeds in TBFM

14

American Institute of Aeronautics and Astronautics 
each run using a modified NASA TLX ${ }^{11}$. The real time ratings were collected by prompting controllers every 3 minutes to rate their workload on a scale of 1 to 6 . The results show that workload was generally adequate with a slightly higher workload for the high altitude controllers than for the low altitude controllers.

Figure 22 shows the average workload over elapsed run time across all runs by sector. The pattern mostly reflects the difficulty/complexity of the arrival traffic scenario. As indicated

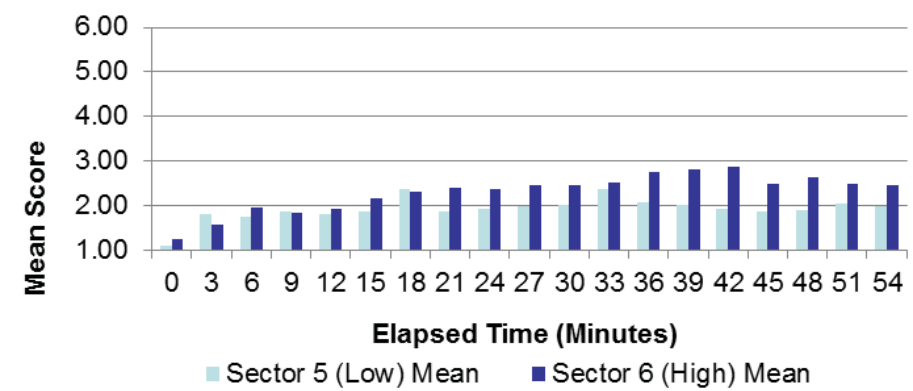

Figure 22: Average WAK ratings across all runs by sector earlier, the scenarios were designed with smaller delays in the beginning and larger delays later in the scenario. Prior research had shown that the scenario difficulty can have a strong impact on controller workload in this environment ${ }^{6}$, which is observed in this study as well.

There were no statistical differences between DCT and $4^{\text {th }}$ line conditions as figures 23 and 24 show.

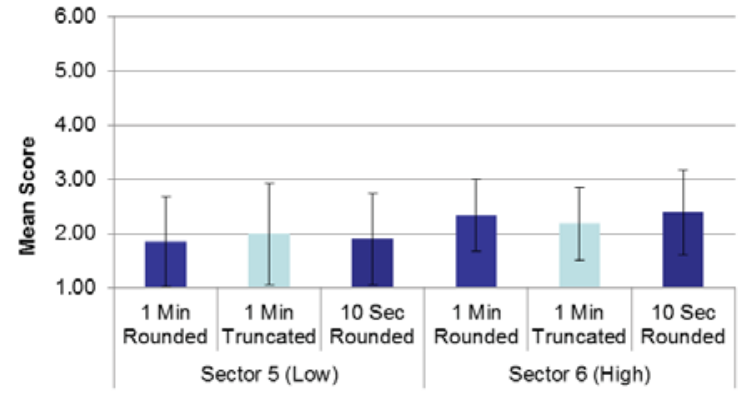

Figure 23: WAK ratings by DCT condition

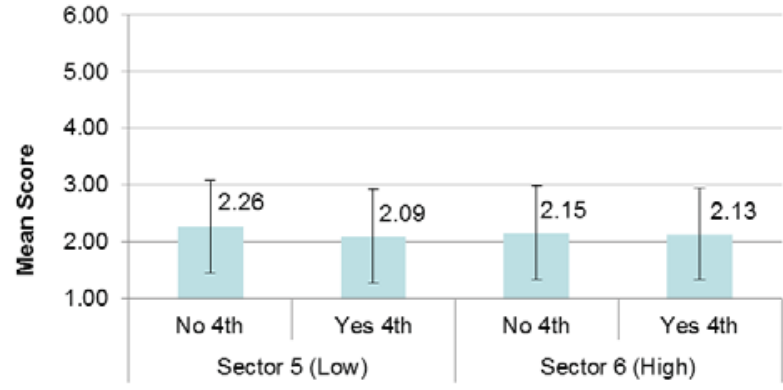

Figure24: WAK ratings by $4^{\text {th }}$ line condition.

A modified NASATLX was conducted after each run. The TLX items were significantly different from each other, but there was no significant interaction or main effect based on the DCT or $4^{\text {th }}$ line condition. The data is shown in Figures 25 and 26.

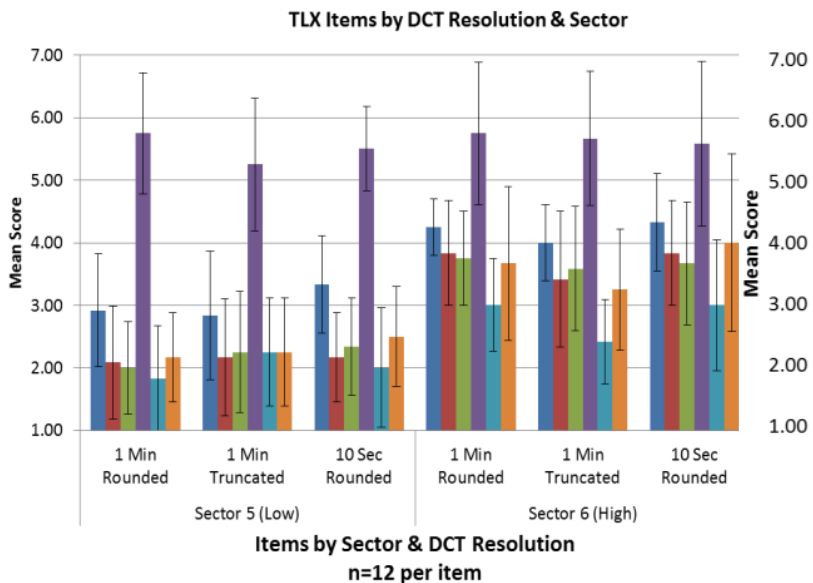

$n=12$ per item

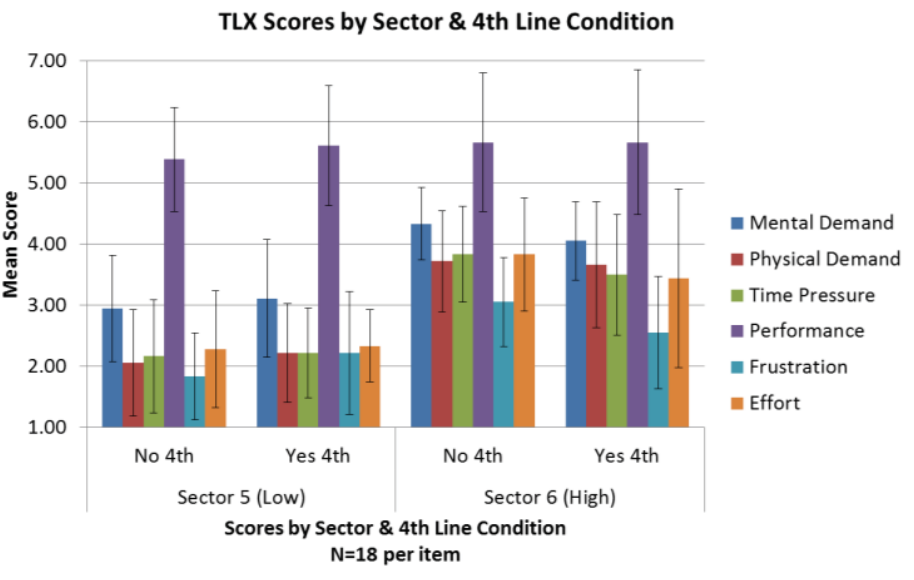

\section{Figure 25: Modified NASA TLX ratings by DCT condition Figure 26: Modified NASA TLX by $4^{\text {th }}$ line cond.}

\section{F. Controller Preference}

After each three run block, controllers were asked the following question: "At this point in the simulation, which DCT resolution do you think overall is most effective for metering operations?" The responses from the 4 controllers are depicted in Figure 27. Figure 27 shows the blocks in chronological order and the count of controller preferences. The notations in the block identify the controller position who had a different preference than the 
others, which differed between blocks; e.g. W1S5, means that the controller in world 1 operating sector 5 had this particular preference.

After the first block, which was run without sending the $4^{\text {th }}$ line speed to TBFM three of the four controllers preferred the " 1 minute rounded" DCT resolution. After the second block with the $4^{\text {th }}$ line speeds used in TBFM and more familiarity with the system there were always at least three of the four controllers who preferred the

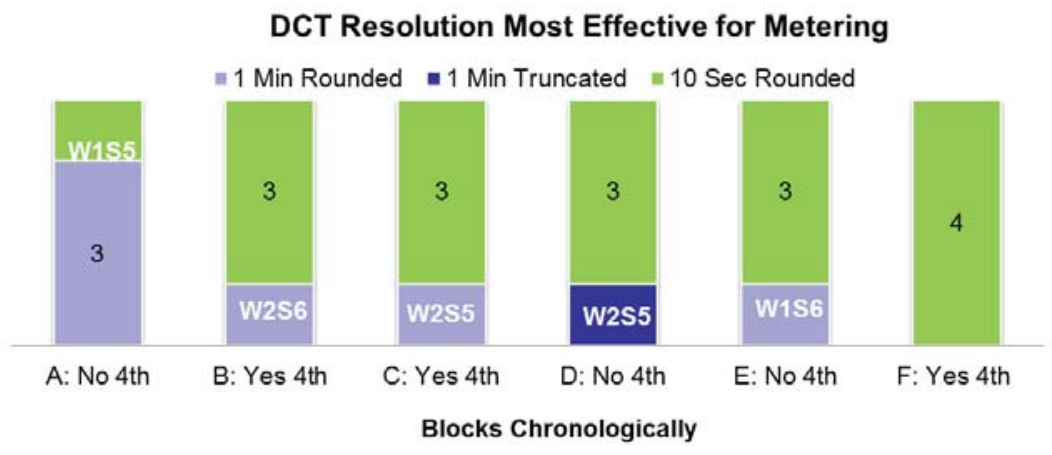

Figure 27: Controllers assessment of the most effective DCT.

10 seconds rounded DCT resolution. After the last block all four controllers stated the " 10 seconds rounded" DCT resolution as their preference. Only one controller never changed his preference.

Some controllers commented on their DCT resolution choice. These comments are provided in table 3.

Table 3: Comments on most effective DCT resolution

\begin{tabular}{|c|c|c|c|c|}
\hline Position & Block 4 & $4^{\text {th }}$ Line & Choice & Comments on DCT Resolution Choice \\
\hline World 1- 05 (ZTL) LoW & A & No 4th & 10 Sec Rounded & most accurate \\
\hline World 1- 05 (ZTL) Low & B & Yes 4th & 10 Sec Rounded & the 10 second rounded is by far the most accurate method of metering \\
\hline World 1- 06 (ZTL) High & $\mathrm{B}$ & Yes 4th & 10 Sec Rounded & $\begin{array}{l}\text { I PREFER THE } 1 \text { MIN ROUNDED BUT, THE } 10 \text { SEC WAS MORE } \\
\text { EFFECTIVE }\end{array}$ \\
\hline World 2- 06 (ZTL) High & B & Yes 4th & 1 Min Rounded & but $10 \mathrm{sec}$ would be good in list \\
\hline World 1- 06 (ZTL) High & $\mathrm{C}$ & Yes 4th & 10 Sec Rounded & I STILL PREFER THE 1 MIN ROUNDED \\
\hline World 1- 05 (ZTL) LoW & $\mathrm{D}$ & No 4th & 10 Sec Rounded & you can get very close to a precise time at the fix \\
\hline
\end{tabular}

At the end of the training and the end of the study the controllers were asked the following two questions:

"Which Delay Countdown Timer (DCT) Resolution do you prefer?"

"Based on what you know of current day controllers \& operations, what would be the most practical combination of DCT resolution and 4th line update to introduce, train, and use? "

Table 4 provides those answers:

Table 4: Preferred and most practical DCT

\begin{tabular}{|c|c|c|c|c|}
\hline & \multicolumn{2}{|c|}{ End of Training } & & \multicolumn{2}{c|}{ End of Study } \\
\hline Position & Preferred DCT & Most Practical DCT & Preferred DCT & Most Practical DCT \\
\hline World 1 ZTL 05 Low & 10 Seconds Rounded & 1 Minute rounded & 10 Seconds Rounded & 10 Seconds Rounded \\
\hline World 1 ZTL 06 High & 1 Minute Truncated & 1 Minute Truncated & 10 Seconds Rounded & 10 Seconds Rounded \\
\hline World 2 ZTL 05 Low & 1 Minute Rounded & 1 Minute Rounded & 1 Minute Rounded & 1 Minute Rounded \\
\hline World 2 ZTL 06 High & 10 Seconds Rounded & 10 Seconds Rounded & 10 Seconds Rounded & 10 Seconds Rounded \\
\hline
\end{tabular}

Even though it was preferred, one controller noted that the "10 seconds rounded" resolution increased the clutter on the controllers' scope and one controller suggested to use 1 minute rounded next to the aircraft's target symbol and 10 seconds in the meter list. Another controller suggested considering using " 1 minute rounded" at the high altitude and "10 seconds rounded" at the low altitude position.

The controllers were also asked after each run how having/not having the $4^{\text {th }}$ line speed update the DCT impacted their overall task/traffic management efficiency. Figure 28 depicts those results. 


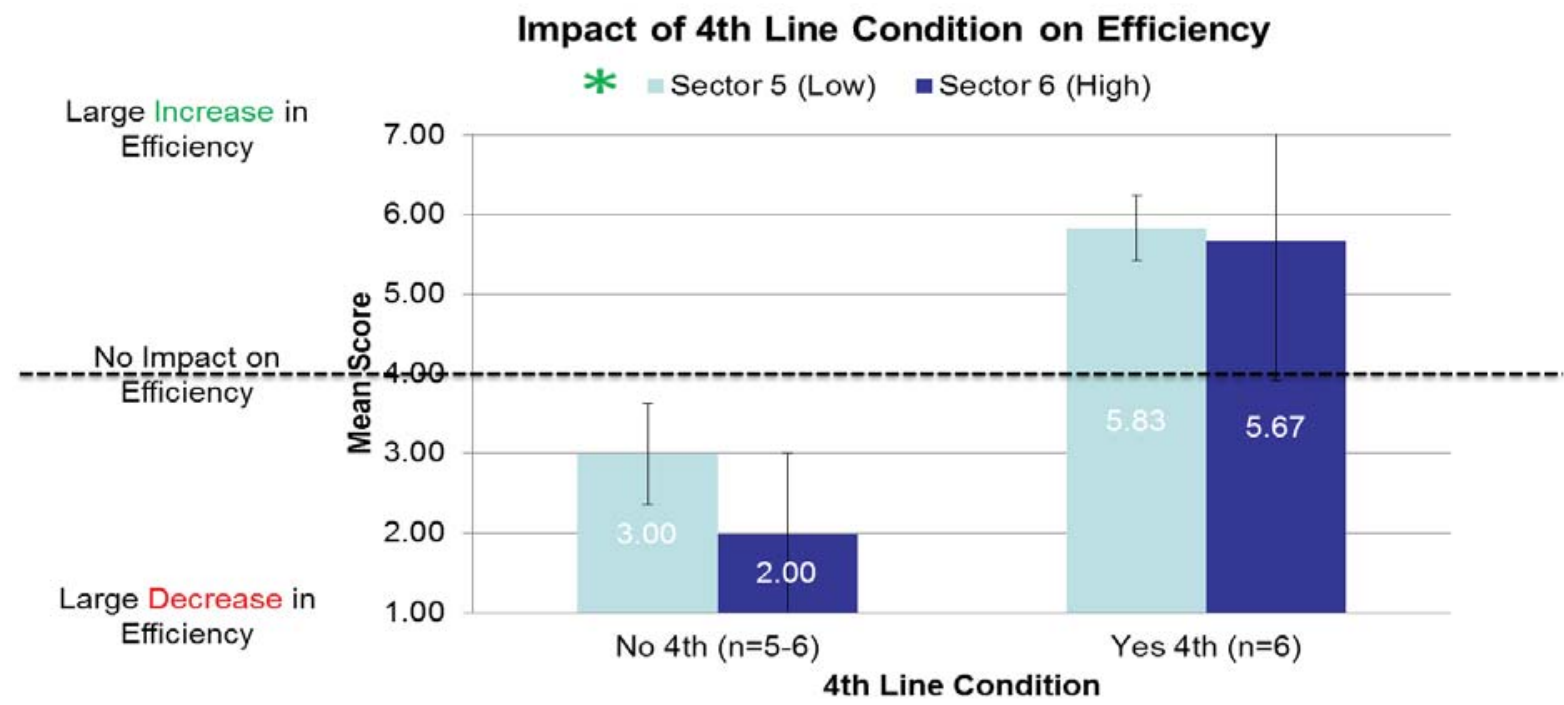

Figure 28: Subjective assessment on whether the $4^{\text {th }}$ line speeds were used in TBFM had an impact on air traffic control efficiency

The controllers reported that having the $4^{\text {th }}$ line speeds being used in TBFM had a positive effect on their air traffic efficiency. This subjective assessment is supported by the objective data presented earlier in this paper that demonstrated the need for fewer instructions and efficiency gains from this condition.

\section{G. Acceptability}

In the end of study questionnaires, controllers were also asked the following acceptability question: "From your point of view, how acceptable is each DCT resolution for current day metering operations when the 4th line does/does not update the DCT?" The results are depicted in Figure 29.

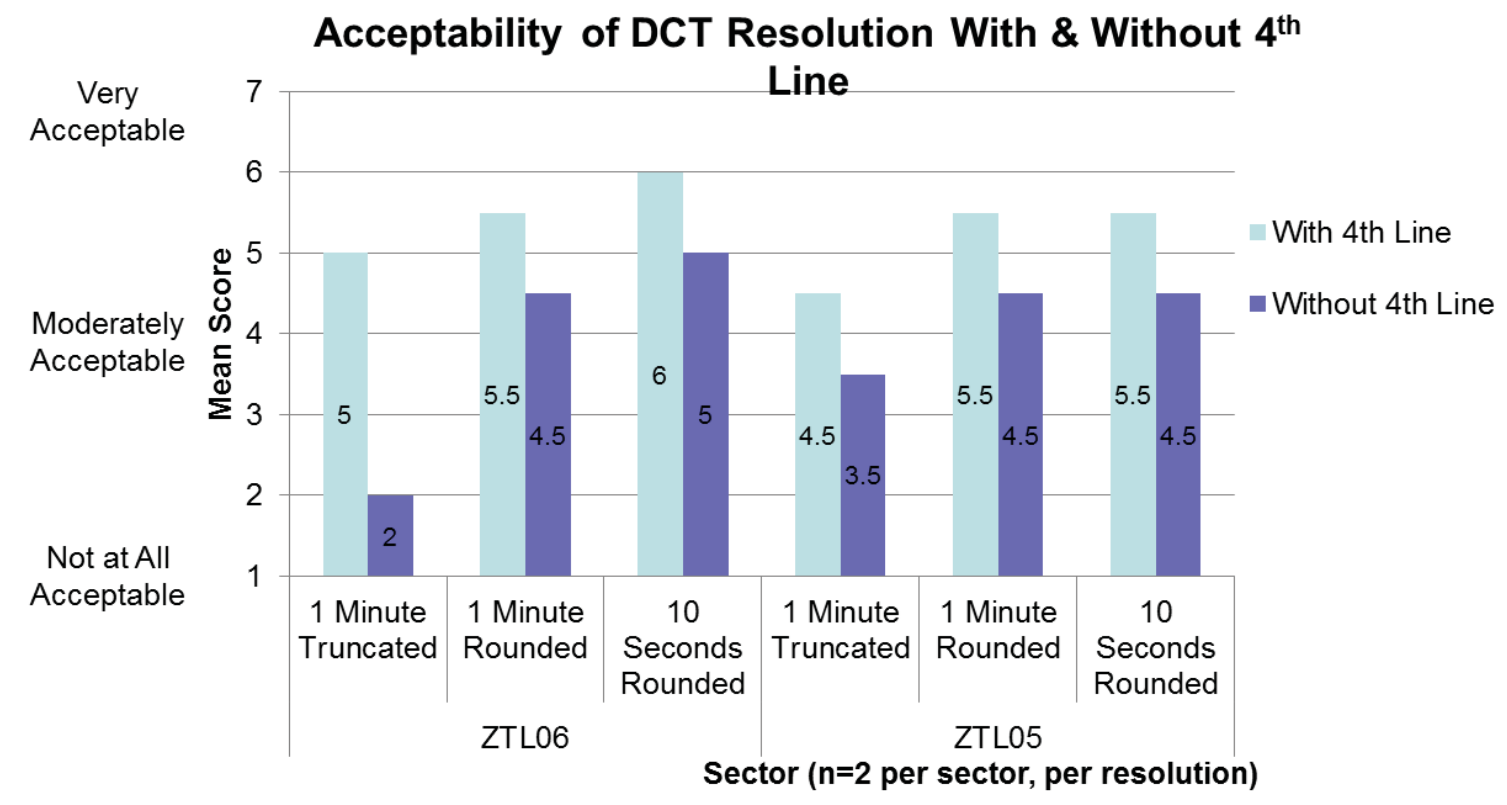

Figure 29: Acceptability of each DCT resolution for metering ops from controller participants

The controllers rated the " 1 minute truncated" without $4^{\text {th }}$ line update to the DCT as not acceptable. " 1 minute rounded" and " 10 seconds rounded" without $4^{\text {th }}$ line update were rated slightly over moderately acceptable. With $4^{\text {th }}$ 
line update all DCT resolutions were rated between moderately and very acceptable with the highest acceptability ratings for the "1 minute rounded" and the " 10 seconds rounded" resolutions.

\section{Conclusion}

The Arrival Metering Precision Study (AMPS) was conducted in the Airspace Operations Laboratory at NASA Ames Research Center to gain insight into two questions relevant for the operational introduction of time-based metering in the terminal airspace as developed under NASA's Air Traffic Management Demonstration-1 (ATD-1) project. The first objective of AMPS was to determine the delivery accuracy for different delay resolution values. Within the simulated environment and constraints the following was found:

All DCT resolutions supported delivering more than $90 \%$ of the arrival aircraft within +/- 60 seconds to the terminal boundary. Only the "1 minute rounded" and "10 seconds rounded" DCT resolutions supported delivering more than $90 \%$ of aircraft within +/-30 seconds to the terminal boundaries. The " 1 minute truncated" DCT resolution supported a $+/-30$ second accuracy only for about $70 \%$ of the arrival aircraft. Most controllers preferred the "10 second rounded" DCT resolution; all controllers found the "1 minute rounded" and the "10 second rounded" resolutions acceptable. The "1 minute truncated" DCT resolution was found to be less than moderately acceptable.

The second objective was to determine the impact of using (the controller entered 4th line) speed intent in TBFM calculations. Within the simulated environment and constraints it was found that having the controller entered $4^{\text {th }}$ line speeds update the DCT had a very positive impact on control and flight efficiency. Without using the $4^{\text {th }}$ line speeds "1 minute rounded" and "10 seconds rounded" DCT resolutions resulted in more air traffic control instructions, additional track miles and fuel burn as compared to the " 1 minute truncated" DCT resolution. Using the $4^{\text {th }}$ line speeds in TBFM reduced the number of air traffic control instructions by $22 \%$, the additional track miles by $15 \%$ to $30 \%$ and the overall fuel burn during a 135 NM long arrival segment by $5 \%$ to $9 \%$. Controllers reported increased efficiency and higher acceptability ratings resulting from using the $4^{\text {th }}$ line speeds.

Based upon these results we recommend (1) using the controller entered $4^{\text {th }}$ line speed to update the delay in TBFM for high and low altitude arrival sectors; (2) letting the controllers/facilities choose their preferred DCT resolution separately in data tag and meter list among the "10 seconds rounded" and the "1 minute rounded" DCT resolutions and (3) eliminating the " 1 minute truncated" DCT resolution in particular when a metering accuracy better than $+/-60$ seconds is desired. 


\section{Appendix}

A. Run schedule. One day of training, 4 days data collection with 18 runs.

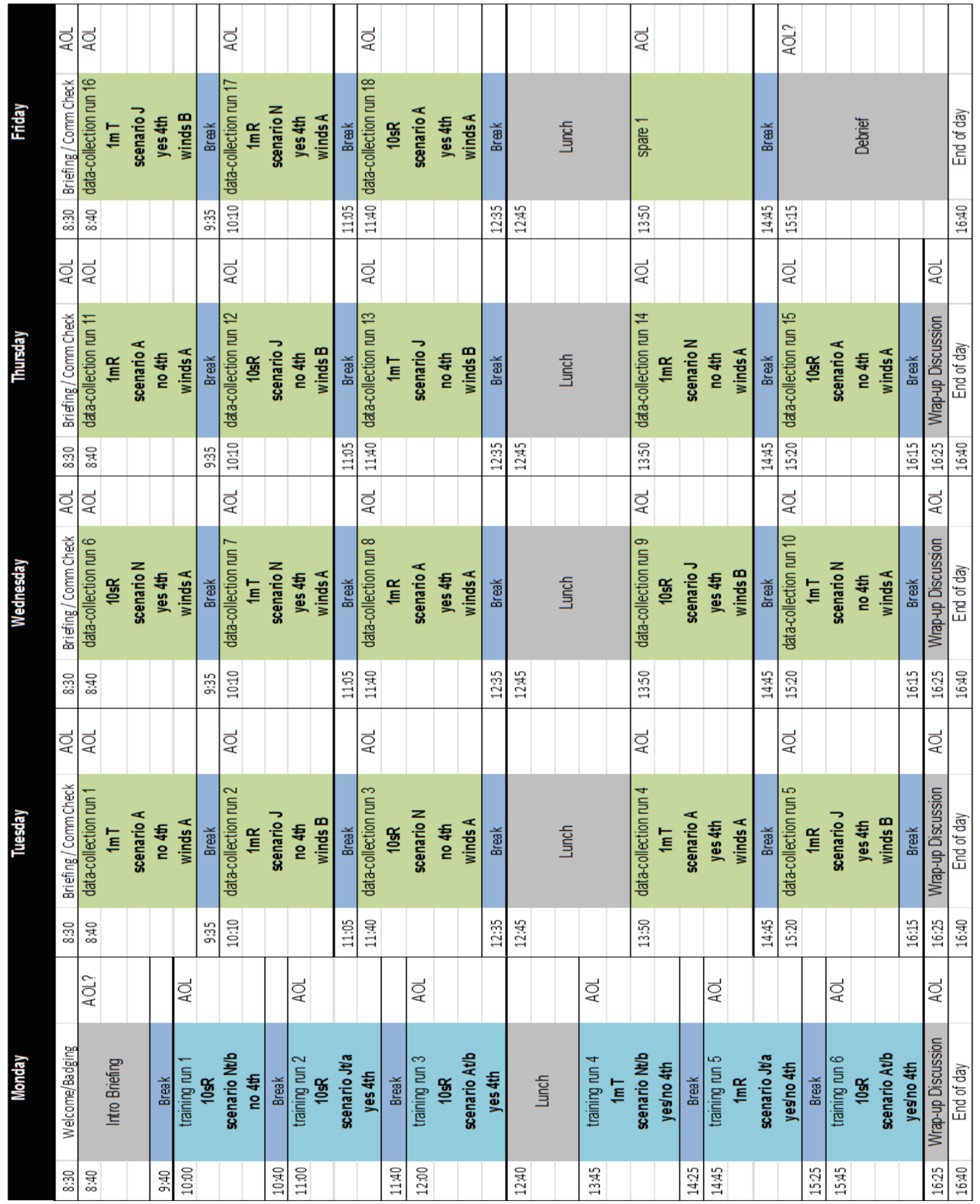




\section{B. Fuel Analysis Methodology}

Since MACS did not have an intrinsic fuel burn model, estimates were made after the simulations were completed by analyzing the actually flown trajectories. The analysis took advantage of the fuel burn models integrated with the Trajectory Synthesizer (TS) ${ }^{8}$ of the Center TRACON Automation (CTAS) ${ }^{9}$.

TS was originally developed to provide aircraft trajectory scheduling support for CTAS. It was later extended to model various flight and pilot procedures with greater flexibility and higher fidelity ${ }^{12}$. TS models an aircraft's trajectory by considering the horizontal path and vertical profile in a decoupled way. The horizontal path consists of segments of straight lines and arcs, whereas the vertical profile, including altitude and speed, consists of segments with distinct transition control settings. TS has a high-fidelity fuel burn model for large commercial jets. TS does not have a high-fidelity model for regional jets, but can be configured to use the Base of Aircraft DAta (BADA) ${ }^{13}$ performance model. This mixture of fuel burn model was adopted for the fuel burn analysis.

The key step to estimate a trajectory's fuel burn was to use TS to build a noise-smoothed, synthesized trajectory that closely fitted the actual trajectory. To do so, the actual trajectory was first analyzed by the CmSimTrackComparer ${ }^{14}$, a research tool that can derive intent information from trajectories. The CmSimTrackComparer identified change points for the horizontal path and the vertical profile (altitude and speed) of the actual trajectory, respectively. These change points broke up the actual trajectory into horizontal and vertical segments that were to be fitted by noise-smoothed segments. The horizontal change points allowed the CmSimTrackComparer to fit the horizontal path with a sequence of straight lines and arcs. Similarly, the vertical change points allowed the CmsimTrackComparer to fit the vertical profile with a sequence of vertical segments. There was more than one way of defining the transition control settings in the vertical segments. For this analysis, each vertical segment has a fixed-flight-path angle and a fixed acceleration with respect to the air. The flight-path angle and acceleration were computed from the beginning and end track points of each segment by

$$
\begin{aligned}
& a=\frac{v_{e}-v_{b}}{t_{e}-t_{b}} \\
& \gamma=\arctan \left(\frac{h_{e}-h_{b}}{s_{e}-s_{b}}\right)
\end{aligned}
$$

Here, $a$ and $v$ stand for acceleration and speed with respect to the air, respectively; $b$ and $e$ are indices for the beginning and end track points, respectively; $t$ is for the track time, $h$ is for the altitude, $s$ is for the path distance defined by the horizontal path (increasing towards the end); and $\gamma$ for the flight-path angle. These vertical segments, combined with the horizontal path segments, allowed the CmSimTrackComparer to create a detailed trajectory request for TS. TS then computed the fuel burn required for flying this trajectory.

Several tolerance parameters were adjusted by trial and error for the segment extraction. For the horizontal path:

- A heading change tolerance was used to determine if a track point was in a turn. This tolerance must be large enough to ignore heading noises and small enough to detect real turns.

- A maximum heading change was used to determine if a track point belonged to an existing turn or a new turn. A smaller value results in finer fitting at the cost of more segments and potential over-fitting. For example, a sharp turn can be modeled as one turn of, say, 180 degrees. Alternatively, it can be modeled as two turns of 90 degrees each, if the maximum heading change is set to 90 degrees. In the latter case, the two turns can have difference radii.

For the vertical profile, the following parameters must be chosen to be large enough to ignore noises and small enough to minimize fitting errors:

- A maximum flight-path angle change was used to determine if a track point belongs to an existing segment or a new segment.

- A maximum acceleration change was used to determine if a track point belongs to an existing segment or a new segment. 
C. Delivery Accuracy Histograms

1. 125NM arc
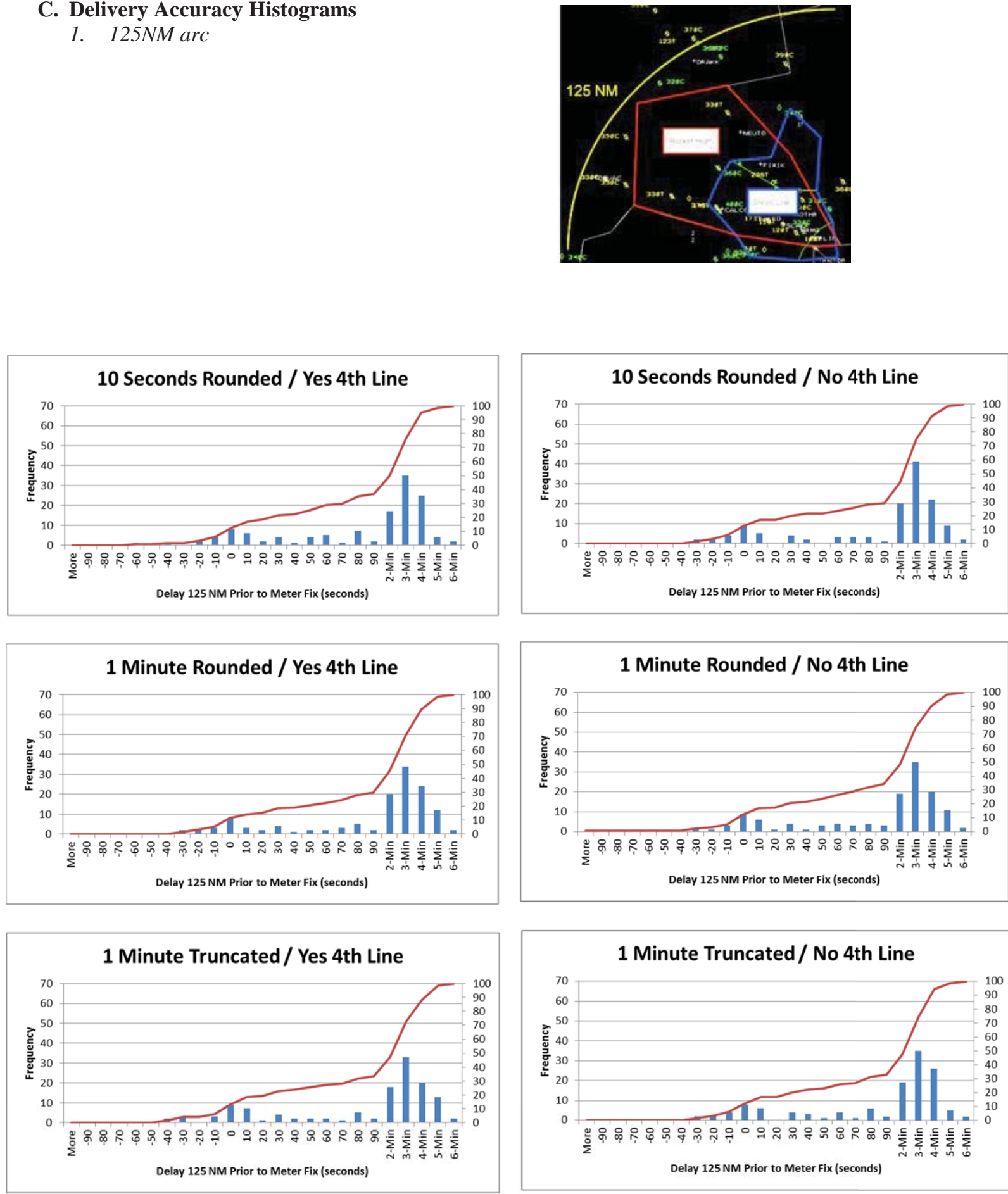

Yes $4^{\text {th }}$ Line:

Number of aircraft per delay bin

Send $4{ }^{\text {th }}$ Line speed to TBFM

DCT updates within seconds

\section{Cundalative tipe:}

$4{ }^{\text {th }}$ Line speed is not send to TBFM Delay updates over time (Current day) 

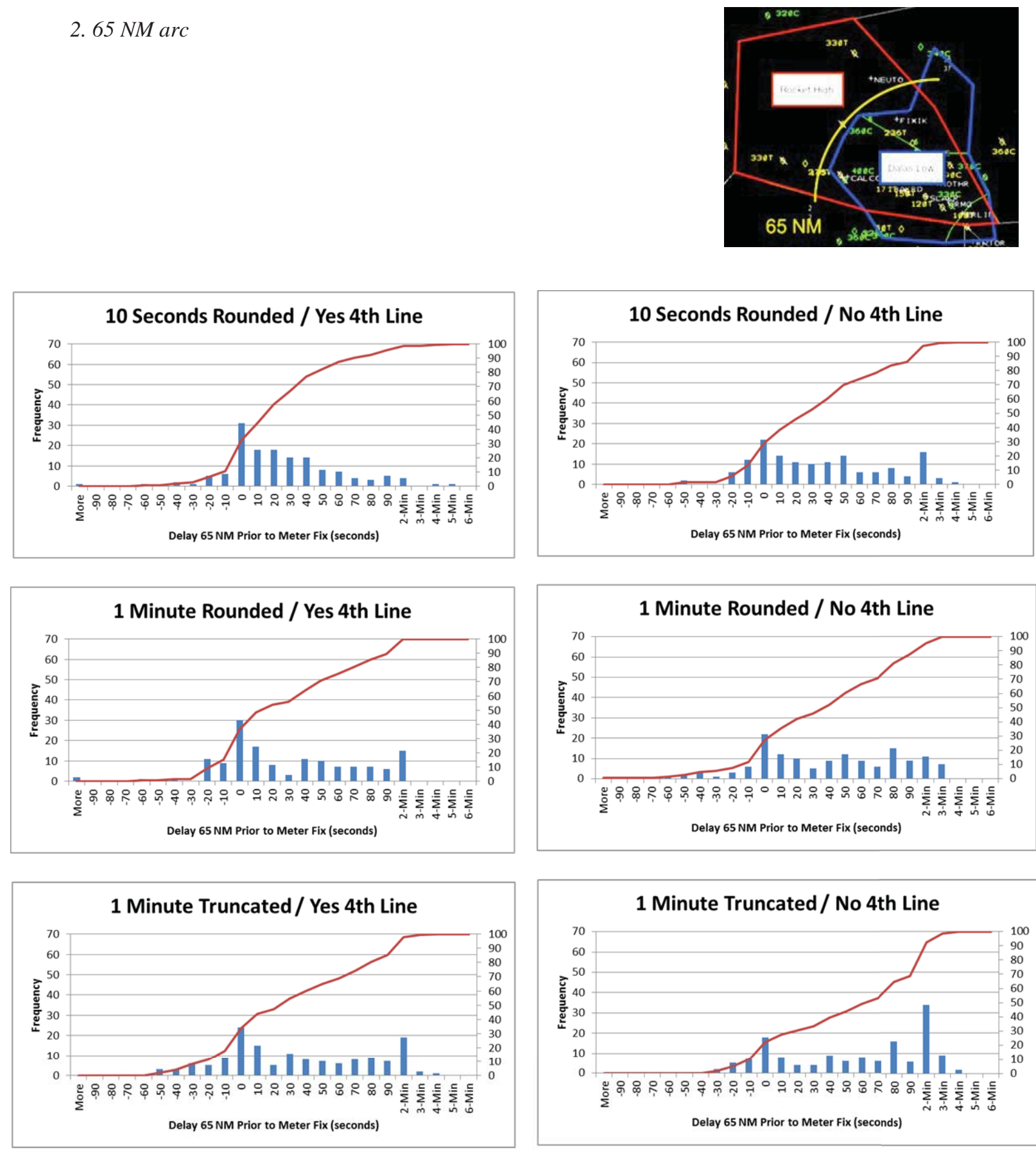

Number of aircraft per delay bin

Cumulative \%

Yes $4^{\text {th }}$ Line:

Send $4{ }^{\text {th }}$ Line speed to TBFM

No $4^{\text {th }}$ Line:

$4^{\text {th }}$ Line speed is not send to TBFM DCT updates within seconds

Delay updates over time

(Current day) 


\section{Acknowledgments}

We greatly appreciate the hard work of the entire AOL staff and all the folks in the human/systems integration division at NASA Ames Research Center that support our work. Moreover, much of the capabilities and research described here is a result of our close collaboration with many colleagues in the Aviation Systems Division at NASA Ames and researchers and developers at NASA Langley Research Center. We greatly appreciate everybody's support. Many thanks also to Danny Vincent and Megan Nealley from Human Solutions for their insights, thorough observations and support during the study. This research was sponsored by the Systems Analysis, Integration, and Evaluation Project of NASA's Airspace Systems Program.

\section{References}

${ }^{1}$ Prevot, T., Smith, N.M., Palmer, E.A., Callantine, T.J., Lee, P.U., Mercer, J.S., Martin, L.H., Brasil, C. and Cabrall C. D. "An Overview of Current Capabilities and Research Activities in the Airspace Operations Laboratory at NASA Ames Research Center” AIAA 2014-2860 , 14th AIAA Aviation Technology, Integration, and Operations Conference, Atlanta GA, June 2014

${ }^{2}$ Prevot, T., Baxley, B., Callantine, T., Johnson, W., Quon, L., Robinson, J., and Swenson, H., "NASA's ATM Technology Demonstration-1: Transitioning fuel efficient, high throughput arrival operations from simulation to reality," in Proceedings of the International Conference on Human-Computer Interaction in Aerospace (HCI-Aero 2012), Brussels, September 2012.

${ }^{3}$ Federal Aviation Administration "NextGen Implementation Plan August 2014" URL: http://www.faa.gov/nextgen/library/media/NextGen Implementation Plan 2014.pdf

${ }^{4}$ Prevot, T. (2002) Exploring the Many Perspectives of Distributed Air Traffic Management: The Multi-Aircraft Control System MACS. In S. Chatty, J. Hansman, \& G. Boy. (Eds). HCI-Aero 2002, AIAA Press, Menlo Park, CA. pp 149-154, 2002.

${ }^{5}$ Mercer, J., Bienert, N Gomez, A. Hunt S, Green S., Prevôt, T. and Wu M.G.. "The Impact of Trajectory Prediction Uncertainty on Air Traffic Controller Performance and Acceptability" AIAA Aviation Conference, AIAA, Reston, VA, 2013.

${ }^{6}$ N. Bienert, J. Mercer, J. R. Homola, S. E. Morey, \& T. Prevot (2014) Case study: Influences of Uncertainties and Traffic Scenario Difficulties in a Human-In-The-Loop Simulation, Proceedings of the 6th International Conference on Research in Air Transportation, Istanbul, Turkey, May 26-30, 2014.

${ }^{7}$ Palmer M and G. Ballin A High-Performance Simulated On-Board Avionics Architecture to Support Traffic Operations Research. AIAA Modeling and Simulation Technologies Conference, AIAA-2003-5452. Austin, TX, 2003

${ }^{8}$ Slattery, R., and Y. Zhao. "Trajectory Synthesis for Air Traffic Automation." Journal of Guidance, Control, and Dynamics 20, no. 2 (March 1997): 232-238.

${ }^{9}$ Erzberger, H., T. J. Davis, and S. M. Green. "Design of center-TRACON automation system." Edited by Andre Benoit. Machine Intelligence in Air Traffic Management. Berlin: AGARD CP-538, 1993. 11.1-11.12.

${ }^{10}$ Stein, E.S. (1985). Air traffic controller workload: An examination of workload probe. (Report No. DOT/FAA/CTTN84/24). Atlantic City, NJ: Federal Aviation Administration Technical Center 2) http://acb220.tc.faa.gov/products/bibliographic/tn8424.htm

${ }^{11}$ Hart S and Staveland L. Development of the National Aeronautics and Space Administration (NASA) Task Load Index (TLX): Results of empirical and theoretical research. In P. Hancock \& N. Meshkati (Eds), Human mental workload (pp139183). Amsterdam, North Holland, 1988.

${ }^{12}$ Lee, A. G., M. G. Wu, and M. Abramson. "Modeling of Complex and Diverse Aircraft Trajectories with the Trajectory Synthesizer Generalized Profile Interface." AIAA-2015-0144, AIAA Modeling and Simulation Technologies Conference. Kissimmee, 2015.

${ }^{13}$ Nuic, A., C. Poinsot, M.-G. Iagaru, E. Gallo, F. A. Navarro, and C Querejeta. "Advanced Aircraft Performance Modeling for ATM: Enhancements to the BADA Model." the IEEE/AIAA 24th Digital Avionics Systems Conference. 2005. 2.B.4-1.

${ }^{14}$ Abramson, M., and K. Ali. Integrating the Base of Aircraft Data (BADA) in CTAS Trajectory Synthesizer. NASA/TM2012-216051, 2012. 